FACULDADE DE FILOSOFIA, CIÊNCIAS E LETRAS DE RIBEIRÃO PRETO

DEPARTAMENTO DE PSICOLOGIA

PROGRAMA DE PÓS-GRADUAÇÃO EM PSICOLOGIA

\title{
Dificuldades para adesão ao tratamento em Centro de Atenção Psicossocial Álcool e outras Drogas: perspectiva do usuário
}

\author{
Larissa Soares de Melo
}

Dissertação apresentada à Faculdade de Filosofia, Ciências e Letras de Ribeirão Preto da Universidade de São Paulo, como parte das exigências para obtenção do título de Mestre em Ciências. Área de concentração: Psicologia em Saúde e Desenvolvimento.

RIBEIRÃO PRETO - SP 



\title{
UNIVERSIDADE DE SÃO PAULO
}

Faculdade de Filosofia, Ciências e Letras de Ribeirão Preto

Programa de Pós-Graduação em Psicologia

Laboratório de Ensino e Pesquisa em Psicopatologia, Drogas e Sociedade

Dificuldades para adesão ao tratamento em Centro de Atenção

Psicossocial Álcool e outras Drogas: perspectiva do usuário

\author{
Larissa Soares de Melo
}

Dissertação apresentada ao Programa de Pósgraduação em Psicologia da Faculdade de Filosofia, Ciências e Letras de Ribeirão Preto da Universidade de São Paulo, para obtenção do título de Mestre em Ciência. Área de concentração: Psicologia em Saúde e Desenvolvimento.

Orientadora: Clarissa Mendonça Corradi-Webster

Ribeirão Preto - SP 

Autorizo a reprodução e divulgação total ou parcial deste trabalho, por qualquer meio convencional ou eletrônico, para fins de estudo e pesquisa, desde que citada a fonte.

Melo, Larissa Soares de

Dificuldades para adesão ao tratamento em Centro de Atenção Psicossocial Álcool e outras Drogas: perspectiva do usuário. Ribeirão Preto, 2020.

Dissertação de mestrado, apresentada à Faculdade de Filosofia, Ciências e Letras de Ribeirão Preto/USP. Área de concentração: Psicologia em Saúde e Desenvolvimento.

Orientador: Corradi-Webster, Clarissa Mendonça

1. Usuários de drogas. 2. Tratamento. 3. Adesão. 4. CAPS ad 



\section{FOLHA DE APROVAÇÃO}

Melo, Larissa Soares de

Dificuldades para adesão ao tratamento em Centro de Atenção Psicossocial Álcool e outras Drogas: perspectiva do usuário

Dissertação apresentada ao Programa de Pósgraduação em Psicologia da Faculdade de Filosofia, Ciências e Letras de Ribeirão Preto da Universidade de São Paulo, para obtenção do título de Mestre em Ciência. Área de concentração: Psicologia em Saúde e Desenvolvimento.

Aprovada em:

\section{Banca Examinadora}

Profa. Dra.

Instituição:

Julgamento:

Profa. Dra.

Instituição:

Assinatura:

Prof. Dr.

Instituição:

Assinatura: 

À minha mãe, meu pai, minha irmã e meu irmão - o meu lugar mais bonito no mundo. Meu ninho de afeto, força e de amor incondicional. 



\section{AGRADECIMENTOS}

À minha mãe Raquel, fonte inesgotável de amor, que com seu antigo fusca branco me mostrou ainda cedo que as pessoas precisavam de cuidado e afeto. E se hoje eu caminho em busca de um mundo justo, é porque dela eu vim. Minha referência, minha inspiração.

Ao meu pai Vanderlito, que com o seu coração sonhador desbravou ainda menino os abismos de São Paulo. Que me mostra diariamente a força e a beleza do nosso povo nordestino. E com o seu amor pelos livros me ensinou sobre luta e liberdade. Meu maestro favorito de Bolero de Ravel.

À minha irmã Luciana e ao meu irmão Rafael, meus maiores presentes de vida, meus companheiros de aventuras, andanças e sonhos. Cada ano que passa eles são o meu reencontro mais esperado. Se hoje meu coração anda solto pelo mundo é porque uma parte de mim está com eles.

Às minhas sobrinhas Sophia e Sienna, que fizeram meu coração crescer e pulsar ainda mais. Vê-las crescer é olhar para o tempo com surpresa e encanto. Ser titia é materializar o amor que tanto sinto, nem lembro mais como é viver sem tê-las.

Ao meu grande amor e companheiro Matheus, que está comigo lado a lado, compartilhando planos, caminhos e certezas, com ele entendi perfeitamente o sentido de presença e leveza. Juntos alçamos voos lindos e reais.

À minha sogra Rosana, ao meu sogro Ocimar e minha cunhada Marina, que trouxeram ainda mais afeto e apoio aos meus dias, os quais não medem esforços para se fazerem presentes. Minha família cresceu, e de um jeito lindo.

À Thais, minha amiga querida, parceira de risadas e Lutas Antimanicomiais. Juntas das trincheiras às bordas infinitas.

À Bruna, por toda sensibilidade e bem querer, com quem evoluo a cada encontro e conversa.

À Francine que foi minha ponte de segurança e referência quando me mudei para Ribeirão Preto/SP, e à Camilla que aqui me acolheu e fez da cidade o meu lar, agradeço por cada palavra e gesto de afeto e cuidado. 
À Aila, Júlia e Patrícia, minhas companheiras de conversas profundas, sinceras e transformadoras, minhas parceiras de crescimento e libertação. Juntas desatamos nós.

À Juliana e Tassiana, minhas amigas de infância e do coração. Sou grata por tanta vida, histórias compartilhadas e dias à beira mar. Minha família caiçara.

À Carolina (Querol), Eloá, Giovanna e Mariana, companheiras de afeto e de profissão, que comigo tecem uma amizade infinita, daquelas que sustentam e salvam. Nascemos nos corredores universitários e transcendemos para a vida, com amor.

Ao Filipe e ao Matheus, meus amigos amados, que estão comigo em todos os momentos e em todas as minhas andanças, me acompanhando, aconselhando e confortando. Eles são o colo e a mão estendida, que sorte a minha.

À minha querida equipe do Centro POP, que comigo trava batalhas para que o cuidado se faça presente e eficiente em rua, e que tanto me apoiou para que aqui eu estivesse.

À Secretaria Municipal de Assistência Social de Ribeirão Preto, em nome da Diretora do Departamento de Proteção Social Especial Marlene Domingues e do Secretário Guido Desinde Filho, por todo suporte e confiança para a realização do meu trabalho.

À todas as pessoas que contribuíram para que esta pesquisa se concretizasse, vivenciei um lindo processo de encontros e reencontros que ampliou a minha rede e a minha própria história.

Aos meus colegas do Laboratório de Ensino e Pesquisa em Psicopatologia, Drogas e Sociedade - LePsis, que comigo compartilharam dúvidas, questionamentos e muito conhecimento.

E principalmente à Prof ${ }^{a}$. Dra ${ }^{a}$. Clarissa M. Corradi-Webster, que me orientou de forma generosa para além do espaço acadêmico, possibilitando o meu crescimento profissional e pessoal de forma potente. Sou grata a este encontro que tanto me transformou. 
Si Può Fare 



\section{RESUMO}

Melo, L.S. (2020). Dificuldades para adesão ao tratamento em Centro de Atenção Psicossocial Álcool e outras Drogas: perspectiva do usuário (Dissertação de Mestrado). Programa de Pós-Graduação em Psicologia, Faculdade de Filosofia, Ciências e Letras de Ribeirão Preto, Universidade de São Paulo, Ribeirão Preto - SP.

Sabe-se que o Centro de Atenção Psicossocial Álcool e outras Drogas (CAPS ad) se configura enquanto um equipamento estratégico de lógica territorial que oferta cuidado às pessoas que fazem uso problemático de álcool e outras drogas, no entanto, a adesão à terapêutica ainda se constitui um grande desafio. Diante da importância do serviço para o Sistema Único de Saúde (SUS) e para toda a comunidade, este estudo teve como objetivo compreender as dificuldades de adesão ao tratamento na perspectiva da pessoa que já frequentou a proposta terapêutica, no entanto, interrompeu o acompanhamento de forma repentina e autônoma, sem estar previsto em seu Projeto Terapêutico Singular (PTS). Além também de buscar compreender caracteríticas das relações com a equipe e demais usuários que dificultaram para a continuidade do cuidado, e investigar quais os motivos que levaram as pessoas a passarem pelo abordagem psicossocial, mas não permanecerem. Para alcançar esse objetivos, foi realizado um estudo qualitativo, descritivo e exploratório, aprovado pelo Comitê de Ética em Pesquisa da FFCLRP-USP. A coleta de dados se deu por meio de entrevistas semiestruturadas com 15 pessoas que relataram vivências em 14 CAPS ad de 13 cidades do estado de São Paulo, as quais foram selecionadas pela técnica de bola de neve e definidas pelo critério de saturação amostral. A partir da análise temática dos dados definiu-se dois temas abrangentes denominados relacionamentos no CAPS ad e CAPS ad como local de passagem, os quais foram divididos em dois manuscritos. Os temas abordam que as relações estabelecidas com os profissionais são reconhecidas enquanto tecnicistas e pouco acolhedoras, mediadas por burocracias e posturas distanciadas, além também de pontuar que as interações entre os pares são identificadas como fatores que colocam em risco a mudança de vida tão almejada. Foram também referidas caraterísticas educacionais, socioeconômicas e drogas de consumo como marcadores que promoveram a não identificação com o contexto. No entanto, ainda sim o CAPS ad foi indicado enquanto um espaço de referência para buscar auxilio quando necessário, propondo um novo olhar diante da adesão ao equipamento, a qual foi identificada pelas narrativas do participantes enquanto um processo que não se desenvolve de forma linear, sendo o CAPS ad uma ferramenta e um local passageiro diante de um cenário ampliado de vida, no qual o cuidado psicossocial se institui enquanto uma das diversas frentes do cotidiano de seus assistidos, os quais possuem autonomia para transitar inclusive diante de outras propostas de tratamento, como também em busca de outros momentos e papéis sociais, inclusive como resultado da própria terapêutica. Contudo, essa dinâmica também se estabelece pelo fato de seus usuários compreenderem o serviço como um espaço de livre acesso, o qual necessita de aprimoramento técnico e institucional, como também de maior investimento para possibilitar uma terapêutica disponível à demanda plural da população que o acessa.

Palavras-chave: Usuários de drogas. Tratamento. Adesão. CAPS ad. 



\begin{abstract}
Melo, L.S. (2020). Difficulties in adhering to treatment in a Psychosocial Care Center Alcohol and other Drugs: user perspective (Dissertação de Mestrado). Programa de Pós-Graduação em Psicologia, Faculdade de Filosofia, Ciências e Letras de Ribeirão Preto, Universidade de São Paulo, Ribeirão Preto - SP.
\end{abstract}

It is known that the Psychosocial Care Center for Alcohol and other Drugs (CAPS ad) is configured as a strategic equipment of territorial logic that offers care to people who make problematic use of alcohol and other drugs, however, adherence to therapy is still constitutes a great challenge. Given the importance of the service for the Unified Health System (SUS) and for the whole community, this study aimed to understand the difficulties of adhering to treatment from the perspective of the person who has already attended the therapeutic proposal, however, interrupted the monitoring of sudden and autonomous form, without being foreseen in its Singular Therapeutic Project (PTS). In addition to seeking to understand characteristics of the relationships with the team and other users that hindered the continuity of care, and to investigate the reasons that led people to undergo the psychosocial approach, but not to remain. To achieve these objectives, a qualitative, descriptive and exploratory study was carried out, approved by the Research Ethics Committee of FFCLRP-USP. Data collection took place through semi-structured interviews with 15 people who reported experiences in 14 CAPS ad in 13 cities in the state of São Paulo, which were selected by the snowball technique and defined by the criterion of sample saturation. From the thematic analysis of the data, two broad themes called relationships in the CAPS ad and CAPS ad were defined as a place of passage, which were divided into two manuscripts. The themes address that the relationships established with professionals are recognized as technicians and not very welcoming, mediated by bureaucracies and distant postures, in addition to pointing out that interactions between peers are identified as factors that put the longed-for life change at risk. Educational, socioeconomic and drug use characteristics were also mentioned as markers that promoted non-identification with the context. However, CAPS ad was still indicated as a reference space to seek assistance when necessary, proposing a new look at the adhesion to the equipment, which was identified by the participants' narratives as a process that does not develop in a linear way, being the CAPS ad a tool and a temporary place in the face of an expanded life scenario, in which psychosocial care is established as one of the diverse fronts of the daily lives of its caregivers, who have the autonomy to transit even when faced with other treatment proposals, but also in search of other moments and social roles, including as a result of the therapy itself. However, this dynamic is also established by the fact that its users understand the service as a space of free access, which requires technical and institutional improvement, as well as greater investment to make available a therapy available to the plural demand of the population that accesses it.

Keywords: Drug users. Treatment. Adherence. CAPS ad. 



\section{LISTA DE FIGURAS}

Figura 1 - Mapa do estado de São Paulo e os 13 municípios relatados pelos participantes da pesquisa.

Figura 2 - Mapa temático que indica o tema principal, os dois temas abrangentes e os subtemas estabelecidos pela análise de dados da pesquisa.

Figura 3 - Mapa temático dos relacionamentos estabelecidos no CAPS ad por seus usuários e que dificultam para a adesão ao tratamento (Manuscrito 1).

Figura 4 - Mapa Temático das principais razões que levaram as pessoas a utilizarem o CAPS ad como local de Passagem (Manuscrito 2).

\section{LISTA DE TABELAS}

Tabela 1 - Relação de Centro de Atenção Psicossocial Álcool e outras Drogas existentes no Brasil.

Tabela 2 - Características do consumo de drogas e da trajetória de tratamento dos participantes da pesquisa.

Tabela 3 - Dados sociodemográficos dos participantes da pesquisa. 



\section{SUMÁRIO}

PERCURSO

1. INTRODUÇÃO

1.1 Histórico e políticas públicas sobre álcool e drogas 31

1.2 O Centro de Atenção Psicossocial Álcool e outras Drogas - CAPS ad 37

1.3 O Centro de Atenção Psicossocial Álcool e outras Drogas e a adesão ao tratamento 42

2. OBJETIVOS 49

2.1 Objetivo Geral 49

2.2 Objetivos Específicos 49

3. MÉTODOS 53

3.1 Delineamento 53

3.2 Local 54

3.3 Participantes 55

3.4 Instrumento 58

3.5 Coleta de dados 59

3.6 Análise dos dados 60

3.7 Considerações éticas 62

4. Dificuldades PARA ADESÃo AO TRATAMENTO EM CENTRO DE ATENÇÃo PSICOSSOCIAL ÁLCOOL E OUTRAS DROGAS: RELACIONAMENTOS NO CAPS AD E CAPS AD ENQUANTO LOCAL DE PASSAGEM 65

5. DISCUSSÃO 71

6. CONSIDERAÇÕES FINAIS 79

7. REFERÊNCIAS 85

APÊNDICES 101

ANEXOS 109 



\section{PERCURSO}

Eu fui a primeira a não aderir ao CAPS ad.

Em abril de 2009 no segundo ano do curso de terapia ocupacional na Universidade Estadual Paulista "Júlio de Mesquita Filho" (UNESP), fui ansiosa e animada para o meu primeiro dia de observação clínica em estágio. Ansiava pelo toque dentro daquele mar de teoria em um curso integral. Queria ver, queria sentir, queria entender. O sorteio realizado pela professora em minha sala de aula designou duplas a espaços em que acompanharíamos por quatro semanas consecutivas uma terapeuta ocupacional em sua atuação cotidiana. Caí no desconhecido CAPS ad. Em uma terça-feira, às 8 horas de uma manhã nublada com leve garoa, fui ao CAPS participar da rotina terapêutica e aprender sobre o equipamento. Entrei. Me apesentei aos profissionais e logo me encaminharam para uma roda, uma roda formada principalmente por homens.

Foi iniciada a primeira atividade do dia. Nessa roda as pessoas se apresentavam dizendo o nome e o tempo de abstinência, e relatavam sobre o seu processo terapêutico e suas vivências diárias. Era um grupo interativo, mas com certa rigidez sobre o sentido de estar bem. Em seguida foi à vez da atividade do grupo operativo. Alguns pediram para assistir televisão, porém os demais pegaram seus tapetes de retalho e continuaram a atividade já iniciada em outro dia. Eu não sabia fazer tapete, mas me aproximei de uma mulher que estava cortando retalhos. Cortava retalhos, colocava em uma agulha de madeira, e perpassava por um pedaço de juta. Ficamos conversando sobre o porquê ela estava ali e há quanto tempo. O tapete ia ganhando forma e tamanho. Acabou o tempo. Despedi-me e informei que retornaria na semana seguinte.

Saí do CAPS andando rapidamente em direção a minha casa que era relativamente longe, optei em não pegar o transporte público, voltei a pé, caminhando entre as subidas e descidas das ruas, acompanhando as subidas e descidas da minha respiração. Precisava andar. Precisava respirar. A ansiedade inicial havia se tornado angustia em meio a espirros constantes em consequência aos retalhos empoeirados do tapete iniciado. No primeiro orelhão liguei a cobrar para 
minha mãe que estava em Santos/SP a $520 \mathrm{~km}$ de mim, já que havia optado em cursar uma universidade pública longe de casa. Era meu sonho! Liguei para minha mãe para dizer o quão frustrante havia sido aquela manhã, e que estava decidida em largar o curso, pois não me identificava e não me via nem em sala de aula, e muito menos naquela rotina prática que me pareceu tão engessada.

Minha mãe sabiamente me aconselhou a respirar e me acalmar, falou que não haveria problema algum caso optasse pelo que havia dito, mas me orientou olhar para o tempo de forma otimista, e que todo processo de aprendizagem havia seus altos e baixos, mas que o saldo era sempre positivo, pois sempre haveria aquisições a partir das reflexões feitas com afeto. Minha mãe encerrou a conversa dizendo que me apoiaria sempre, e que queria me ver feliz no que escolhesse. Escolhi continuar o curso a partir do que estava vivenciando na vida universitária. Pessoas que haviam entrado em minha vida, a universidade que tanto amava transitar ouvindo e conversando meio a tantos sotaques. Uma universidade que respirava diversidade e possibilidades. Fiquei pelo que sentia no coletivo e não em si pelo que sentia em sala de aula.

Com o passar do tempo (aquele que minha mãe havia dito) fui desenvolvendo uma nova relação com o curso. Conheci a saúde mental. A teoria me aguçou conhecimento, queria saber mais. Aprendi que a história da minha profissão estava entrelaçada com a saúde mental, e até então um curso que me deixava em dúvida passou a dar sentido(s). Todas optativas foram na área. Meu trabalho de conclusão de curso foi na área. Meu último estágio no meu último ano no curso, coincidentemente, foi na área. A saúde mental passou a fazer do meu repertório formativo. Estudar e falar sobre reforma psiquiátrica, RAPS, luta antimanicomial me moveram ao (re)encontro com o meu entendimento sobre o que era ser terapeuta ocupacional. Formei-me T.O, e feliz!

Em seguida iniciei a residência multiprofissional em saúde mental também em outra universidade pública, na Faculdade de Medicina de Marília (FAMEMA). A saúde mental havia me deixado com vontade de ampliar meu conhecimento e minha prática. Minha primeira pós-graduação me permitiu isso: vivência intensa na perspectiva multiprofissional em saúde mental. Foram dois anos mergulhados vivendo a RAPS de diversas maneiras. Olhando para diversas vidas de diversas 
maneiras. Enxergando vida. Enxergando possibilidades. Nisso, aquele mesmo CAPS ad de 2009 ressurgiu em 2012 no meu cotidiano, agora não como estudante de terapia ocupacional, mas sim como terapeuta ocupacional pós-graduanda. Três anos depois me encontrava novamente ansiosa, no entanto agora não mais para as quatro semanas que passei por lá, mas, dessa vez ansiosa para os seis meses que permaneceria atuando 40 horas semanais no equipamento.

Ao chegar, muita coisa se mantinha igual, no entanto, outras não mais. O CAPS havia mudado para um local menor, com uma estrutura física que se aproximava de um posto de saúde, em oposição à ampla casa que abrigava o equipamento três anos atrás. Outro fator que tinha mudado; não havia terapeuta ocupacional atuando no espaço no momento da minha chegada, e a equipe me deu autonomia para desenvolver toda rotina terapêutica da minha prática. Iniciei o processo com a participação da minha querida equipe de residentes multiprofissionais. Era minha primeira vez desenvolvendo uma rotina terapêutica do zero, e toda a teoria até então estudada começou a ganhar forma em meio a atividades grupais e individuais. Um mês depois a nova terapeuta ocupacional contratada chegou ao CAPS ad, e com ela continuei esse processo autônomo, trocando e adquirindo conhecimento, construindo e ampliando propostas de cuidado. Ampliando e cuidando também da minha prática profissional. Ampliando e cuidando do CAPS.

Em 2012 minha história no CAPS ad recomeçou. (Re)começou envolta por todo o tempo que eu havia esperado passar e acalmar. Envolto por tudo o que havia escutado, lido, aprendido e praticado. Fiquei seis meses no CAPS, vivenciando as histórias de cada pessoa que ali buscava por cuidado. Histórias marcadas por rompimentos, por idas e vindas, histórias de tentativas, erros e acertos. Vidas! Vida como a minha! Nesses seis meses pude explorar minha profissão com muita curiosidade e muito afeto, ampliando meu interesse pela prática na área de drogas, passando a buscar outras vivências para ampliar o olhar diante da política de drogas.

A residência me possibilitou realizar um estágio eletivo. Busquei o Departamento de Psiquiatria da Universidade Federal de São Paulo (UNIFESP) a fim de vivenciar o Programa de Orientação e Atendimento a Dependentes, o PROAD, em São Paulo/SP. Queria conhecer e ver de perto sobre o cuidado em redução de danos que tanto lia, mas pouco via no dia a dia. Um mês passou de 
forma rápida e intensa. Aprendi muito! Aprendi ao ponto de mudar e expandir. Aprendi ao ponto de reconstruir e ressignificar novamente minha prática profissional. Voltei para Marília para finalizar mais uma etapa do meu processo formativo. Finalizei a residência apresentando meu trabalho de conclusão de curso a partir da oficina terapêutica que havia desenvolvido no CAPS ad. Uma atividade terapêutica que falava sobre habilidades. Que estimulava habilidades pessoais e individuais, habilidades não mais vinculadas com o uso de drogas. Pouco falávamos sobre elas, sobre as drogas. Falávamos muito sobre eles!

Após a residência meu primeiro trabalho como terapeuta ocupacional foi com pessoas que buscavam internação em hospital como meio de cuidado ao uso abusivo de drogas. Queria compreender o outro lado tido como cuidado fundamental para muitos. Eu, enquanto pessoa que se identifica e vê muita potência no cuidado comunitário, achei necessário explorar o outro lado como forma de aprender e entender. Foram dois anos de muitas desconstruções. Vivencie o sofrimento em suas diversas fases e faces. Vivenciei o cuidado cru e nu, em que a criatividade se fazia inventiva na busca por recursos terapêuticos. Entendi de forma visceral de onde vinham e para onde iam todas aquelas pessoas que buscavam por ajuda.

Pessoas estas que até então ficavam envoltas apenas por paredes hospitalares, foram levadas enquanto intervenção terapêutica às paredes da oficina cultural do município de Marília, mas dessa vez não mais como pacientes, e sim como pintores certificados e reconhecidos enquanto artistas por diversos veículos da mídia local. Realizamos conjuntamente a quebra de muros e de paradigmas por meio de muita tinta, pincel, T.O e afeto. Todo inconsciente tomou forma e cores. Novamente pouco falamos sobre drogas. Falamos sobre pessoas e suas habilidades!

Até que em 2016 o Projeto Redes (SENAD/FIOCRUZ) entrou em minha vida trazendo uma grande mudança de emprego e de município. Sai de Marília/SP e fui para a desconhecida Ribeirão Preto/SP trabalhar. Eu que sempre estive na ponta do cuidado, atuando diretamente onde a política pública acontece, passei a trabalhar na perspectiva da gestão, onde tudo se inicia. Passei a articular a política de drogas em um amplo território, tecendo cuidadosamente a rede intersetorial de cuidado. Uma rede potente e complexa. Uma rede cheia de vida! 
Por dois anos articulei conhecimento, diálogo e espaços pensando e fazendo política de drogas na saúde, na assistência social, na segurança pública, na educação, na universidade, na sociedade civil. Teci a política de drogas para fora e para mim. Dois anos que mais um CAPS ad passou a fazer parte da minha rotina diária de trabalho. Dessa vez, não mais "somente" como T.O. Fazia supervisões de equipe, discussões de caso, discussões sobre o fluxo do usuário de drogas na rede de cuidado e o papel do CAPS nesse processo. Passei a vivenciar o CAPS ad na perspectiva do desenvolvimento da política de drogas no território, e toda a complexidade e dificuldade que se fazem presentes no cenário. Um novo olhar surgiu, o dos bastidores, e com isso novos questionamentos. A partir desses questionamentos senti a necessidade de explorá-los dentro de uma lupa, de forma ampliada e minuciosa. E desse sentimento nasce o meu feliz encontro com a Professora Dra. Clarissa Mendonça Corradi-Webster.

Ainda em 2016, enquanto articuladora, aproximei-me do Laboratório de Estudo e Pesquisa em Psicopatologia, Drogas e Sociedade, o LePsis, sob a coordenação da professora Clarissa, com intuito de trazer a Universidade de São Paulo (USP) para as discussões que o Projeto Redes estimulava no território, a fim de sustentar os espaços intersetoriais de modo consistente. E dessa relação, no segundo semestre de 2017, em meu último período como articulado intersetorial, nasceu a minha relação com o LePsis como pós graduanda. Tornei-me mestranda com objetivo de investigar uma das principais demandas encontradas enquanto trabalhava: a adesão dos usuários aos CAPS ad. Ao buscar na memória lembrei-me deste como um tema central em todos os CAPS que passei. E pensando na importância histórica e estratégica do equipamento e tudo o que ele representa simbolicamente no processo da reforma psiquiátrica no país, eu e a professora Clarissa iniciamos o processo de pesquisa. E dentro de toda essa rede que construí ao longo dos anos, realizei diversos contatos em busca de pessoas que pudessem e se interessassem em participar da minha pesquisa. E durante essa busca revisitei todo meu percurso até aqui. Um percurso tecido cuidadosamente em rede, como um tapete, como aquele tapete de 2009 quando o CAPS ad passou a fazer parte da minha vida.

Um percurso que ainda estou tecendo... 



\section{Introdução}





\section{INTRODUCÃ̃}

Esta pesquisa propõe compreender, sob a perspectiva do usuário, dificuldades para dar continuidade ao tratamento em um Centro de Atenção Psicossocial Álcool e outras Drogas (CAPS ad). Para contextualizar o tema pesquisado, será realizada uma análise histórica sobre o desenvolvimento das políticas públicas sobre álcool e drogas no Brasil e sobre as compreensões a respeito do cuidado ofertado aos usuários de drogas. Será feito um panorama dos serviços propostos a partir da Reforma Psiquiátrica e da literatura que analisa a adesão dos usuários aos CAPS ad. Após esta revisão de literatura, serão explicitadas as técnicas utilizadas para o desenvolvimento deste estudo.

\subsection{Histórico e políticas públicas sobre álcool e drogas}

No Brasil, os problemas associados ao uso problemático de álcool e outras drogas começaram a receber atenção do Estado no início do século 20 (1920). No entanto, as primeiras propostas de abordagem, intervenção e assistência foram originalmente desenvolvidas predominantemente pelo campo da justiça e da segurança pública, compreendendo as condutas associadas à produção, ao comércio e ao uso de drogas como um ato criminoso e moralmente incorreto (Mota \& Rozani, 2013).

É importante ressaltar que essas medidas de caráter proibicionista foram influenciadas e reforçadas, ao longo do século XX, por convenções e conferências internacionais, entre elas as da Organização Nacional das Nações Unidas (ONU), em que se recomendavam medidas punitivas e de controle ao consumo de drogas ilícitas. Em 1911 o país adotou à Convenção de Haia, Primeira Conferência Internacional do Ópio, que definiu e estabeleceu internacionalmente o controle da comercialização de três substâncias: morfina, heroína e cocaína (Lima, 2009). No ano de 1924 o Código Penal Brasileiro, por meio do decreto 4.294, propôs pena de prisão para aqueles que vendessem ópio, seus derivados e cocaína. Nos anos de 1961, 1971 e 1988, o Brasil compareceu as reuniões da $\mathrm{ONU}$, as quais originaram tratados internacionais que reafirmavam a necessidade de ações repreensivas à problemática (Machado \& Miranda, 2007). 
No decorrer do tempo, a partir da década de 70, essas características passaram a ser influenciadas pelo saber médico, mais especificamente pela psiquiatria, que surgiu como outra forma de respaldo técnico contribuindo para legitimar as medidas que compreendiam o usuário de drogas como doente e/ou criminoso (Fiore, 2005). Para tratar o usuário de drogas foram propostos equipamentos públicos ou filantrópicos de cunho assistencial, como os hospitais psiquiátricos e centros especializados, reforçando o processo de patologização e também de exclusão dos usuários (Dimenstein \& Bezerra, 2011).

Ao associar o uso de substâncias a questões de justiça e da segurança pública, criminalizando o usuário, ampliou-se a lacuna existente entre a saúde pública e esses sujeitos, de forma que as alternativas de cuidado passaram a reproduzir a lógica da repressão, trazendo inicialmente propostas baseadas em internações prolongadas de caráter fechado e excludente, tendo como foco a "cura" por meio da abstinência total do uso. Esse olhar contribuiu para o surgimento de diversos dispositivos tidos como único recurso terapêutico aos usuários de drogas, como por exemplo, os hospitais psiquiátricos, criados para prestar assistência a um cenário carente e desassistido (Vaissman, Ramôa, \& Serra, 2008).

Desta forma, os estigmas associados às pessoas que fazem uso de substâncias foram reforçados, dificultando sua inserção social (Ministério da Saúde, 2003). Machado e Miranda (2007) compreendem que este processo contribuiu fortemente para a indefinição acerca da implantação de ações de políticas públicas na área de álcool e outras drogas no país, influenciando a forma como o tema ainda é visto e tratado até nos dias atuais.

Esse modelo de atenção ofertado até então como única perspectiva aos usuários no Brasil, está alinhada a política proibicionista-belicista que surgiu no início do século XIX nos EUA, conhecida como "guerra às drogas" (war on drugs), declarada em 1971 pelo presidente da época Richard Nixon, a partir do crescimento exponencial da produção e do consumo de bebida alcoólica no país. O proibicionismo está atrelado a dois fatores que explicam o consumo de substâncias: a perspectiva moral/criminal que compreende a questão como uma prática delituosa cujo enfrentamento consiste no encarceramento; e no modelo de doença, a qual refere o uso abusivo de substâncias psicoativas como uma patologia biologicamente determinada e que para tal é necessário 
tratamento e reabilitação, porém ambas as perspectivas compartilham o propósito final de eliminação do uso da substância (Tammi \& Hurme, 2007; Wodak, 2009).

No entanto, a partir da década de 80, com o início da Reforma Psiquiátrica no país, que propunha um novo modelo de cuidado à saúde mental, pautando-se na perspectiva da desinstitucionalização e desconstrução dos manicômios, buscando a desospitalização, o cuidado dos desassistidos e a desconstrução do paradigma da loucura (Amarante \& Torres, 2001), a concepção dos problemas associados ao uso de drogas no discurso político mostra-se mais ampliada, passando a ser compreendida também como uma questão de saúde pública (Garcia, Leal \& Abreu 2008; Machado \& Miranda, 2007; Wandekoken \& Siqueira, 2011). Visão esta que foi reforçada por pesquisas que começaram a identificar o uso de substâncias como possível causador de extensos danos que impactavam diferentes aspectos ocupacionais da vida humana (família, violência e crime, trânsito e segurança), tornando-se também uma ameaça à segurança pública (Holder, 1997). Com isto, a partir da última década, diversos estudos passaram a fomentar e a evidenciar a necessidade de políticas públicas específicas para a problemática (Casswell, 2000).

A partir da construção de novos conceitos em saúde mental, foi proposto o desenvolvimento de metodologias e práticas de assistência e cuidado, que buscavam e estimulavam a autonomia, reinserção social e valorização da singularidade das pessoas em sofrimento psíquico (Gonçalves \& Sena, 2001). Sendo assim, em 1989, foi apresentado o primeiro Projeto de Lei (3.657) proposto pelo deputado federal Paulo Delgado, que proibia a construção de novos hospitais psiquiátricos pelo poder público, que fiscalizava via judiciário as internações compulsórias e previa o investimento para a criação de recursos terapêuticos extra hospitalares.

Porém, somente em 2001, essas mudanças foram aprovadas por meio da Lei 10216, conhecida como a Lei da Reforma Psiquiátrica Brasileira. Em 2002, visando por em prática essa substituição de modelo de atenção, o Ministério da Saúde publicou a Portaria $n^{\circ} 336 / 2002$ com intuito de credenciar e financiar serviços que visassem à atenção psicossocial como linha de cuidado, contribuindo para o investimento e ampliação da atenção à saúde mental, fortalecendo nacionalmente os Centros de Atenção Psicossocial (CAPS) pelo país (Brasil, 2003). 
No mesmo ano, com objetivo de reduzir a lacuna histórica de ausência estatal e de políticas públicas para a prevenção e assistência ao usuário de drogas, o Ministério da Saúde, em concordância com as recomendações da III Conferência Nacional de Saúde Mental (Dezembro de 2001), referiu a necessidade de políticas públicas específicas para os usuários de álcool e outras drogas e implementou o Programa Nacional de Atenção Comunitária Integrada aos Usuários de Álcool e outras Drogas (Portaria GM / 816 de 30 de abril de 2002) (Ministério da Saúde, 2002). Neste documento é reconhecido que o uso prejudicial de substâncias é um grave problema de saúde pública que tange a saúde mental, desenvolvendo uma política específica para o tema baseadas nos direitos humanos, nos princípios e diretrizes do Sistema Único de Saúde e da Reforma Psiquiátrica (Lima, 2008).

Concomitante a esse movimento de redirecionamento do tema e do cuidado para o escopo da saúde pública, ocorreram também mudanças significativas no cenário político. Até o ano de 1998 o Brasil não apresentava uma Política Nacional específica sobre Drogas com objetivo de reduzir a demanda e oferta pelo território. Somente a partir da realização da XX Conferência das Nações Unidas em que se discutiu especificamente o tema, que o país iniciou um processo de mudança efetivo em suas diretrizes e sua organização (Brasil, 2018).

$\mathrm{O}$ até então existente Conselho Federal de Entorpecentes (CONFEN) transformou-se no Conselho Nacional Antidrogas (CONAD), o Sistema Nacional de Prevenção, Fiscalização e Repressão de Entorpecentes também foi alterado para Sistema Nacional Antidrogas (SISNAD), no entanto, preservando os mesmos objetivos; e criou-se a Secretaria Nacional Antidrogas (SENAD), ligada especificamente a Casa Militar da Presidência da República (Alves, 2009).

Em 2002, com a responsabilidade de articular a política Nacional Antidrogas pelo território, buscando a integração do governo e da sociedade, a SENAD ativou diversos atores envolvidos com a temática para reformular e desenvolver a política brasileira. No dia 26 de agosto de 2002, por meio de Decreto Presidencial $n^{\circ} 4.345$, foi instituído a Política Nacional Antidrogas (PNAD) do país (Ministério da Justiça, 2002).

No decorrer dos primeiros anos da PNAD o tema se manteve em evidência, havendo a necessidade de se reavaliar a política diante das diversas mudanças pelo qual 
o país e o mundo estavam passando. Em 2004, foi realizado o $1^{\circ}$ Seminário Internacional de Políticas Públicas sobre drogas, concomitantemente a outros fóruns nacionais e regionais sob a organização e cuidados da SENAD, responsável pela articulação nacional do tema (Ministério da Justiça, 2004).

Esse movimento diante da temática contou com a participação social e embasamento político científico, apresentando também como resultado a retirada do prefixo "anti"drogas, guiado pelo movimento internacional e nacional acerca do tema, instituindo-se assim a Política Nacional sobre Drogas (PNAD). A PNAD passa então a estabelecer de modo articulado, os fundamentos, diretrizes e estratégias voltadas para a redução da demanda e da oferta de drogas no país (Ministério da Justiça, 2004).

Já no mês de agosto de 2006, por meio da Lei $\mathrm{n}^{\circ}$ 11.343, o Sistema Nacional Antidrogas foi alterado para Sistema Nacional de Políticas Públicas sobre Drogas, o qual manteve mesma sigla (SISNAD), no entanto, realizou significativas alterações baseadas nos avanços científicos e transformações sociais da época, contribuindo para o destaque do país no cenário internacional, e para importantes mudanças no território brasileiro (Supera, 2017).

Considerando toda complexidade e instabilidade que envolve a política de drogas e consequentemente o cuidado ofertado ao usuário de drogas devido às diversidades culturais e sociais existentes no Brasil, e da alta incidência de transtornos mentais causados pelo uso abusivo e/ou dependência de substâncias lícitas ou ilícitas, adotou-se como estratégia de políticas públicas a ampliação de acesso ao tratamento, buscando a compreensão integral e dinâmica do problema, a promoção dos direitos e a abordagem de redução de riscos e de danos. Desta forma, o Ministério da Saúde investiu na ampliação dos Centros de Atenção Psicossocial Álcool e outras Drogas (CAPS ad) pelo território brasileiro, considerando-o como o principal dispositivo de tratamento para a demanda, e que também atua como ferramenta nas ações de prevenção e promoção da saúde (Brasil, 2005).

No ano de 2011, buscando ampliar os pontos de atenção às pessoas com necessidades decorrentes do uso de crack, álcool e outras drogas, o Ministério da Saúde instituiu a Rede de Atenção Psicossocial (RAPS) por meio da portaria 3088/2011 (Brasil, 2011). Na RAPS são incluídos outros dispositivos de cuidado, ressaltando a 
importância da atenção primária em saúde e fortalecendo o papel dos CAPS ad em diálogo com os demais níveis de complexidade, de modo a ampliar o acesso da população e garantir a articulação e interlocução dos dispositivos de saúde, desenvolvendo uma rede de atenção ao usuário de drogas no território.

A rede de atenção aos usuários de álcool e outras drogas foi constituída a partir dos princípios da Reforma Psiquiátrica, articulada com diversos serviços substitutivos ao hospital psiquiátrico dentro de uma perspectiva integral por meio de uma rede viva, a qual tem por objetivo acolher a pessoa em sofrimento, buscando sua emancipação e reinserção social. A Rede ad se desenvolve a partir da saúde mental no âmbito da atenção básica em saúde, tendo como porta de entrada as Unidades Básicas de Saúde e a Estratégia de Saúde da Família (Brasil, 2004; Ronzani, 2010; César, 2011).

No ano de 2004, a Portaria $\mathrm{N}^{\circ} 2.197$ (Ministério da Saúde) redefine, amplia e pluraliza a rede aos usuários de álcool e outras drogas no Sistema Único de Saúde (SUS), estabelecendo como principais componentes da rede de atendimento: a Atenção Básica $(\mathrm{AB})$ constituída pelas Unidades Básicas de Saúde, Consultórios na Rua e Núcleos de Apoio à Saúde da Família (NASF); os CAPS ad e CAPS ad III; Atenção de Urgência e Emergência composta pelo SAMU e UPA 24 horas; Atenção Hospitalar de Referência composta por Serviço Hospitalar de Referência para a Atenção Integral aos Usuários de Álcool e outras Drogas (SHR-ad) ou Enfermaria Especializada em Hospital Geral; Ambulatórios; e a Rede de Suporte Social que são associações de ajuda mútua e entidades da sociedade civil que complementam à rede disponibilizada pelo SUS, gerando uma rede intersetorial de cuidado e atenção (Siqueira \& Silva, 2014).

No entanto, no mês de abril de 2019, com a mudança de gestão da União a partir das eleições presidenciais realizadas em outubro de 2018, o Governo Federal promulgou a nova Política Nacional sobre Drogas (PNAD), Decreto $n^{\circ}$ 9.761, sob a articulação e coordenação da Secretaria Nacional de Cuidados e Prevenção às Drogas do Ministério da Cidadania e a Secretaria Nacional de Políticas sobre Drogas do Ministério da Justiça e Segurança Pública, a qual revogou inteiramente o Decreto $n^{\circ} 4.345$ que até então orientava à lei brasileira (Secretaria Geral da Presidência da República, 2019).

A partir desta mudança, pontos significativos da PNAD foram alterados interferindo inclusive na constituição da RAPS, e da própria Política e Saúde Mental. O novo decreto retira à Política de Redução de Danos como prática norteadora para o 
cuidado do usuário de drogas, e determina a abstinência como foco central da abordagem terapêutica, além também de reconhecer as Comunidades Terapêuticas enquanto os equipamentos de referência para o cuidado dos usuários de drogas, ampliando o investimento orçamentário e o número de vagas de internação por todo o país. A atual Política Nacional sobre Drogas tem como meta a busca por uma sociedade protegida do uso de drogas lícitas e ilícitas, por meio de um trabalho realizado em conjunto entre os Ministérios da Cidadania, da Saúde, da Justiça e Segurança Pública, dos Direitos Humanos, da Família e Mulher, entretanto, as práticas de acolhimento e tratamento ficarão sob a orientação e coordenação do Ministério da Cidadania (Diário Oficial da União, 2019).

No entanto, dentro dos princípios, diretrizes e estratégias da Reforma Psiquiátrica, espera-se que a Rede ad desenvolva assistência continua extra-hospitalar de modo articulado com os diferentes níveis de complexidade apresentados pela demanda, buscando a integração social e familiar da pessoa que faça uso problemático de drogas. E que o recurso para internação seja de curta duração e em hospitais gerais, os quais devem ser utilizados apenas quando os recursos externos não apresentarem a devida resolutividade, evitando assim a cronificação e isolamento dos usuários, tendo o CAPS ad um papel estratégico na organização dessa Rede (Brasil, 2010; Ronzani, 2010; César, 2011).

\subsection{O Centro de Atenção Psicossocial Álcool e outras Drogas - CAPS ad}

Os CAPS ad tem se constituído como um dos principais serviços de articulação da política de álcool e outras drogas. Estes são considerados dispositivos assistenciais que abrangem diversas práticas terapêuticas, considerando a heterogeneidade da problemática e do sujeito em tratamento, por meio de uma proposta baseada em serviços comunitários e apoiada por leitos psiquiátricos em hospital geral, trabalhando dentro da perspectiva estratégica de redução de riscos e de danos sociais e à saúde, seguindo os pressupostos da Reforma Psiquiátrica (Ministério da Saúde, 2003).

Os CAPS ad são implantados em municípios com população acima de 70 mil habitantes, com indicadores epidemiológicos relevantes e são organizados de acordo com a demanda populacional local. Indica-se que sua equipe técnica mínima seja composta por 13 profissionais, sendo: um médico psiquiatra; um enfermeiro com 
formação em saúde mental; um médico clínico, responsável pela triagem, avaliação e acompanhamento das intercorrências clínicas; quatro profissionais de nível superior entre as categorias de psicólogo, assistente social, enfermeiro, terapeuta ocupacional, pedagogo ou outro profissional necessário ao projeto terapêutico; e seis profissionais de nível médio sendo técnico e/ou auxiliar de enfermagem, técnico administrativo, técnico educacional e artesão (Portaria n. ${ }^{\circ}$ 336/GM Em 19 de fevereiro de 2002 - Ministério da Saúde).

A equipe multiprofissional busca se articular por meio da realização e interpretação de uma leitura ampliada do indivíduo, que busca por acolhimento e tratamento, a assistência prestada ao usuário de drogas no CAPS ad oferece atendimento personalizado por meio das modalidades de tratamento intensivo, semi-intensivo e não intensivo. A modalidade intensiva compreende que a pessoa necessita de acompanhamento diário podendo inclusive ser integral, já o semi-intensivo se destina as pessoas que necessitam do atendimento frequente, mas nem sempre diário, e por fim a modalidade não intensiva, a qual está direcionada às pessoas que podem ter uma frequência menor, comumente associada ao processo final do acompanhamento psicossocial (Brasil, 2004).

Além da modalidade de acompanhamento também se estrutura e desenvolve o cuidado incluindo as seguintes atividades: atendimento individual (medicamentoso, psicoterápico, de orientação, entre outros); atendimento em grupos (psicoterapia, grupo operativo, atividades de suporte social, entre outros); atendimento em oficinas terapêuticas; refeições diárias, visitas e atendimentos domiciliares e atendimento à família, visando à integração e permanência destes sujeitos aos serviços de saúde (Brasil, 2004).

Os CAPS ad possuem a tarefa de articular os serviços e o fluxo de cuidado de um município, além da realização do matriciamento para os demais serviços não especializados, eles realizam o acompanhamento longitudinal do usuário por meio do cuidado baseado em um Projeto Terapêutico Singular (PTS) o qual é desenvolvido a partir do contexto de vida individual, englobando aspectos familiares e territoriais (Aberta, 2017). Eles aparecem como parceiros primordiais para o cuidado compartilhado na rede de atenção aos usuários de drogas, a qual é formada pela rede de atenção à saúde, atenção psicossocial, da assistência social, setores estratégicos e os 
recursos comunitários, articulando a atenção ao usuário de drogas a partir dos princípios do Sistema Único de Saúde (SUS) e Sistema Único da Assistência Social (SUAS) (Costa, Mota, Paiva \& Ronzani, 2015).

O Centro de Atenção Psicossocial Álcool e outras Drogas até o ano de 2017 era classificado em duas modalidades, CAPS ad II e CAPS ad III, os quais se distinguem no período de funcionamento, e na capacidade de atendimento diante do grupo populacional do município em que está instituído. O CAPS ad II tem capacidade operacional para atender uma população entre 70 mil e 200 mil habitantes, de segunda a sexta-feira, 8 horas por dia, subdivididas em dois turnos. Já o CAPS ad III amplia a atuação como retaguarda a uma população de 200 a 300 mil habitantes, atuando 24 horas, inclusive aos finais de semana e feriados (Ministério da Saúde, 2017).

O CAPS ad III além do cuidado ambulatorial dentro das três modalidades de tratamento descritas anteriormente, também oferta leito para acolhimento noturno, com estrutura física para no mínimo 8 acolhimentos e no máximo 12, os quais podem durar até 14 dias inseridos em um contexto mensal. Os critérios para acolhimento devem ser baseados em aspectos clínicos e/ou psicossociais, devendo-se considerar o fator de risco que a pessoa está inserida no momento do atendimento inicial.

No dia 21 de setembro de 2017 por meio da publicação da Portaria No 3588 instituiu o CAPS ad IV destinado a prestar assistência específica as pessoas em cenas abertas de uso de drogas, locais conhecidos como "cracolândia", em municípios com população acima de 500 mil habitantes. Define-se que o equipamento funcione 24 horas por dia e em todos os dias da semana inclusive aos finais de semana e feriado, devendo atender integralmente adultos ou crianças e adolescentes, diretrizes estas também preconizadas ao CAPS ad III (Ministério da Saúde, 2017).

Os novos equipamentos podem ser classificados em dois tipos, CAPS ad IV Novo ou CAPS ad IV Reestruturado, este último sendo a adaptação de um CAPS ad já pré-existente, e segundo as diretrizes de funcionamento eles devem se desenvolver de forma articulada tanto com a Rede de Atenção às Urgências e Emergências, como também com as equipes de Consultório na Rua para de fato atuar de forma aproximada e vinculada com as pessoas nas cenas abertas de uso (Ministério da Saúde, 2017). 
Para o funcionamento e atendimento 24 horas o CAPS ad IV necessita dispor ao menos de uma equipe mínima composta por 1 profissional que desempenhe atividades e funções administrativas, 1 médico clínico diarista, 2 médicos psiquiatras, sendo um deles plantonista de 12 horas, 2 enfermeiros com experiência e/ou formação na área de saúde mental, sendo também um plantonista 12 horas, 6 profissionais de nível superior, entre eles: psicólogo, terapeuta ocupacional, assistente social, educador físico; 6 técnicos de enfermagem plantonistas 12 horas e 4 profissionais de nível médio. Para o turno noturno orienta-se 1 médico psiquiatra, 1 enfermeiro também com formação na área de saúde mental e 6 técnicos de enfermagem, todos atuando como plantonistas 12 horas (Ministério da Saúde, 2017).

Segundo os esclarecimentos do Ministério da Saúde (2019) sobre as mudanças na Política Nacional de Saúde Mental e nas Diretrizes da Política Nacional sobre Drogas referente a Nota Técnica $n^{\circ}$ 11/2019-CGMAD/DAPES/SAS/MS, o incentivo financeiro destinado para implantação de um CAPS ad IV Novo é de R $200.000,00$ (duzentos mil reais), e para a implementação de um CAPS ad IV Reestruturado é de R\$ 125.000,00 (cento e vinte cinco mil reais). Para o custeio mensal de um CAPS ad IV plenamente estruturado e funcionando e credenciado junto à Área Técnica de Saúde Mental do DAPES/SAS/MS estima-se R \$ 400.00,00 (quatrocentos mil reais).

Já o recurso financeiro fixado destinado aos CAPS ad II é de R \$39.780,00 (trinta e nove mil, setecentos e oitenta reais) mensais com um custeio em média de $\mathrm{R} \$$ 43,00, usuário/mês ao Governo Federal (Guimarães \& Rosa, 2019). O custo mensal determinado ao CAPS ad III é de $\mathrm{R} \$ 78.800,00$ (setenta e oito mil e oitocentos reais), valor este alterado em setembro de 2013 por meio da portaria $\mathrm{N}^{\circ} 1966$, até então o repasse por mês direcionado ao equipamento estava determinado em R \$ 105.000,00 (cento e cinco mil reais) mensais (Ministério da Saúde, 2013).

Atualmente, segundo o levantamento de dados realizado em dezembro de 2019 pela Coordenação Geral de Saúde Mental, Álcool e outras Drogas (Dapes/SAPS) do Ministério da Saúde, existem 447 CAPS ad funcionando em todo país, sendo eles 330 CAPS ad II, 116 CAPS ad III e 1 CAPS ad IV, dos quais a maioria se concentra nos estados da Bahia, Ceará, Minas Gerais, Pernambuco, Paraná, Rio de Janeiro, Rio Grande do Sul, Santa Catarina e São Paulo, como indica a tabela a seguir: 
Tabela 1 - Relação de Centro de Atenção Psicossocial Álcool e outras Drogas existentes no Brasil

\begin{tabular}{|c|c|c|c|}
\hline \multicolumn{4}{|c|}{ Centro de Atenção Psicossocial Álcool e outras Drogas - CAPS a } \\
\hline Quantitativo por UF & CAPS ad II & CAPS ad III & CAPS ad IV \\
\hline $\mathbf{A C}$ & 0 & 1 & 0 \\
\hline $\mathbf{A L}$ & 2 & 1 & 0 \\
\hline $\mathbf{A M}$ & 1 & 1 & 0 \\
\hline AP & 1 & 1 & 0 \\
\hline BA & 18 & 4 & 0 \\
\hline $\mathbf{C E}$ & 22 & 4 & 0 \\
\hline DF & 4 & 4 & 0 \\
\hline ES & 4 & 1 & 0 \\
\hline GO & 8 & 2 & 0 \\
\hline MA & 7 & 0 & 0 \\
\hline MG & 40 & 22 & 0 \\
\hline MS & 3 & 1 & 0 \\
\hline MT & 5 & 0 & 0 \\
\hline PA & 6 & 1 & 0 \\
\hline PB & 6 & 9 & 0 \\
\hline PE & 13 & 6 & 0 \\
\hline PI & 6 & 2 & 0 \\
\hline PR & 25 & 10 & 0 \\
\hline RJ & 23 & 5 & 0 \\
\hline $\mathbf{R N}$ & 7 & 2 & 0 \\
\hline RO & 1 & 0 & 0 \\
\hline $\mathbf{R R}$ & 0 & 1 & 0 \\
\hline $\mathbf{R S}$ & 31 & 13 & 1 \\
\hline SC & 13 & 2 & 0 \\
\hline $\mathbf{S E}$ & 3 & 2 & 0 \\
\hline SP & 79 & 18 & 0 \\
\hline TO & 2 & 3 & 0 \\
\hline TOTAL & 330 & 116 & 1 \\
\hline
\end{tabular}

Fonte: Ministério da Saúde, Coordenação Geral de Saúde Mental, Álcool e outras Drogas - CGMAD/DAPES/SAPS/MS 
No entanto essa rede é considerada insuficiente para atender à demanda cada vez mais crescente, a qual data sua origem oficialmente em 1996 no município de Natal, no estado do Rio Grande do Norte, local em que foi implementado o primeiro CAPS ad no país, e utilizado como parâmetro para o reconhecimento e efetivação do mesmo enquanto dispositivo estratégico para o cuidado da pessoa usuária de álcool e outras drogas (Silva, 2009).

Porém, além do dispositivo ser quantitativamente inferior a necessidade, nota-se também, segundo Bezerra e Dimenstein (2008), é que na prática os CAPS aparecem como realidades distantes dos serviços de atenção básica, havendo uma comunicação pouco articulada e quase inexistente, promovendo o isolamento desses equipamentos técnicos no território e reforçando a ideia de que são os únicos serviços responsáveis pelo atendimento e cuidado do usuário de álcool e outras drogas, e como consequência a demanda acaba concentrada, gerando serviços sobrecarregados e distanciando o papel estratégico que o CAPS tem na organização da rede.

Costa, Ronzani e Colugnati (2017) referem-se a esta dinâmica como “Capsolização", em que o CAPS ad está posicionado e atuando de forma centralizada tanto pela dinâmica imposta pelos dispositivos existentes para o cuidado da população que faz uso problemático de álcool e outras drogas, como também pela própria organização estrutural da política de saúde mental e álcool e outras drogas, característica essa também já apontada anteriormente por Amarante (2003) o qual fez uso do termo "Capsização".

\subsection{O Centro de Atenção Psicossocial Álcool e outras Drogas e a adesão ao tratamento}

Neste capítulo falaremos sobre a adesão para caracterizar a dificuldade de continuidade explorada por esta pesquisa como um fator que interfere no tratamento ofertado pelo Centro de Atenção Psicossocial Álcool e outras Drogas, no entanto, não utilizaremos referência de tempo para determinar este período, consideraremos a não adesão como a saída repentina do CAPS ad sem ter sido apontada e discutida no contexto do Projeto Terapêutico Singular (PTS), se aproximando da definição indicada pela Organização Mundial da Saúde (OMS), a qual pontua que a adesão reflete a 
relação de parceria e vínculo entre a pessoa atendida/cuidada com a equipe profissional que a acompanha, discutindo e construindo conjuntamente a proposta terapêutica (WHO, 2003).

Observa-se que, mesmo havendo investimento e esforço para desenvolver e aplicar políticas públicas específicas às pessoas que fazem uso prejudicial de álcool e outras drogas, a adesão ao tratamento reporta um grande desafio no que concerne ao processo de reabilitação, sendo consenso na literatura o baixo índice de adesão, já que muitos iniciam, mas poucos continuam em acompanhamento nas instituições (Ferreira, Capistrano, Souza, Borba, Kalinke \& Maftum, 2015), sendo esta considerada uma característica universal do usuário de drogas (Malvezzi, Gerhardinger, Santos, Toledo \& Garcia, 2016). Essa perspectiva mostra-se evidente em uma pesquisa desenvolvida no CAPS ad do estado do Piauí, realizada com 227 usuários de drogas em tratamento, a qual verificou que 56,8\% abandonaram a proposta terapêutica (Monteiro, Fé, Moreira, Albuquerque, Silva \& Passamani, 2001). Reis (2016) também aponta, que de uma amostra constituída por 40 pessoas que recorreram ao CAPS ad na cidade de São Paulo para cuidar do uso problemático de drogas, 90\% evadiu em menos de 3 meses, sendo identificado o primeiro mês como o período de maior ruptura.

Esse cenário também se comprova internacionalmente, pois nos Estados Unidos da América estima-se que entre 20 a $70 \%$ dos indivíduos que iniciam o tratamento psicossocial não o concluem (Gearing, Townsend, Elkins, El-Bassel \& Osterberg, 2014), e que menos de $25 \%$ da população com problemas relacionados ao consumo abusivo de álcool buscam algum tipo de ajuda ou tratamento (Tucker, 2001). No Canada também foi identificado que apenas 1 pessoa em cada 3 com o mesmo quadro buscam ajuda especializada (Cunninghama \& Breslina, 2004). Enquanto isso, outro estudo realizado na Espanha revelou que dentre os 57 usuários de substâncias que estavam em uma unidade de reabilitação, 52,9\% abandonaram à terapêutica em um período de até seis meses (Casares-López, González-Menéndez, Festinger., FernándezGarcía, Fernández-Hermida, Secades, \& Matejkowski, 2013).

Na Austrália, Digiusto e Treloar (2007) apontam que apenas uma pequena proporção de usuários de álcool e outras drogas procuram e participam efetivamente do tratamento, e afirmam que as barreiras de acesso constituem efeitos inibidores na busca pelo mesmo, principalmente quando o perfil de uso ainda é caracterizada como inicial, 
em que os problemas e as consequências ainda são identificadas como mínimas pelo próprio usuário. Teesson, Baillie, Lynskey, Manor e Degenhardt (2006) ao compararem o país com os E.U.A reafirmaram a baixa adesão aos serviços de cuidado em ambas as nações, apontando que os australianos não eram mais propensos a procurarem ajuda profissional do que os americanos. Enquanto isso nos EUA apenas 10\% (Wu, Hoven, Tiet, Kovalenko \& Wicks, 2002) dos adultos com problemas por uso abusivo de álcool obtiveram e aderiram o tratamento, aumentando ainda mais esse índice quando identificado o gênero masculino.

Ambos os países apresentam um indicativo de busca por profissionais liberais como meio de ajuda, diferindo apenas na especialidade buscada. Enquanto na Austrália busca-se com maior frequência médicos de família ou clínicos gerais, os americanos quase igualmente consultam-se com um clínico geral, com um psiquiatra ou com um psicólogo. No entanto, ambas nacionalidades não buscam e/ou aderem a um serviço especializado.

No estudo conduzido por Monteiro et al (2001), verificou-se que quanto maior a faixa etária, maior era a média de permanência no tratamento, característica também confirmada por Teesson et al (2006) que identificou que homens com idade superior a 44 anos buscavam e aderiam mais a proposta terapêutica. Cunninghama e Breslina (2004) também reconheceram que quanto maior o nível de gravidade do uso de álcool e outras drogas, maior a possibilidade de adesão à terapêutica.

Malvezzi et al. (2016) ao conversarem com profissionais de um CAPS ad apontaram que, para estes, a qualidade do vínculo do usuário com a equipe, o reconhecimento da vontade de se tratar e a compreensão da abstinência eram fatores primordiais para a adesão do indivíduo ao tratamento. Em relação à responsabilidade da equipe para auxiliar na adesão, os profissionais destacaram a busca ativa dos faltosos, a confecção do projeto terapêutico singular, o cuidado integral e o trabalho em equipe multidisciplinar.

Entretanto Shiokawa (2010) aponta que não há na literatura estudos específicos que confirmem e comprovem a eficiência e resolutividade dos Centros de Atenção Psicossocial Álcool e outra Drogas, e mesmo que o discurso de reconhecimento à importância do equipamento seja positivo, apenas uma minoria dos usuários completa o tratamento e obtém alta por melhora do quadro, indo de encontro ao que afirmam 
Pereira, Amorim, Vidal, Falavigna e Oliveira (2013), de que o principal motivo para evasão ao tratamento na área de saúde mental é o uso de drogas.

Segundo Fikri-Benbrahim, García-Cárdenas, Sáez-Benito, Gastelurrutia, Faus, Schneider e Aslani, (2009), a não adesão é um fenômeno que constitui um grande problema, especialmente de doenças crônicas, sendo que os resultados positivos e a eficácia de qualquer intervenção dependem estritamente da adesão e comprometimento do sujeito. Segundo Nock e Ferriter completar o cuidado na abordagem psicossocial é um componente fundamental para a melhora e para o reconhecimento da efetividade e dos benefícios de um tratamento em saúde mental (2005).

No entanto, diversos fatores podem influenciar a procura por um tratmento adequando, incluindo cuidados de saúde, infraestrutura, grau de debilidade, perfil socioeconômico e atitudes individuais em relação à própria saúde mental (Gearing, Townsend, Elkins, El-Bassel \& Osterberg, 2014). De acordo com Gearing et al. (2014), a não adesão ao tratamento psicossocial contribuí para o enfraquecimento do sistema de saúde mental e para o agravamento do quadro de sintomas, além de gerar um aumento considerável nos custos direcionados ao cuidado.

E para além das questões técnicas e orçamentárias advindas como reflexo da não adesão, a problemática da saúde pública também afeta diretamente a qualidade de vida das pessoas que buscam por tratamento e de seus familiares, contribuindo para agravamento do quadro, debilidade, rompimento de relações tanto pessoais como profissionais, internações recorrentes e baixa motivação terapêutica e de vida (Ferreira, Borba, Capistrano, Czarnobay \& Maftum, 2015).

Para Gearing et al. (2014), a adesão ao tratamento psicossocial recebe pouquíssima atenção científica em comparativo a influência da adesão à medicação nos resultados de saúde, sendo essa amplamente investigada. E vale ressaltar que o tema em questão está diretamente ligado ao processo avaliativo dos equipamentos no campo da saúde mental, e segundo Wetzel e Kantorski (2004) estratégias como esta ainda não se instituíram enquanto tradição no país, diferentemente do que ocorre internacionalmente, e ao explorar especificamente a área de álcool e outras drogas observa-se escassez ainda maior.

Sendo assim, se faz urgente a busca por produção científica que explore a temática para além dos critérios quantitativos e burocráticos, que segundo Pitta et all (1995) são predominantes na área. Orienta-se explorar mais critérios qualitativos que 
considerem os diversos olhares dos diversos atores que estão diretamente ligados a este processo de cuidado, principalmente as pessoas que acessam o equipamento do SUS em busca de atendimento especializado, pois quanto maior for o conhecimento acerca dos fatores que interferem e levam a este comportamento de não adesão, maior será a possibilidade de reestruturação e de ampliação da modalidade terapêutica ofertada (Lima \& Schneider, 2013). 


\section{Objetivos}





\section{OBJETIVOS}

\subsection{Objetivo Geral}

Este estudo tem por objetivo compreender as dificuldades encontradas para adesão ao tratamento proposto nos Centro de Atenção Psicossocial Álcool e outras Drogas sob a perspectiva do indivíduo que buscou atendimento no serviço, mas o deixou de forma repentina.

\subsection{Objetivos Específicos}

a) Compreender características das relações com a equipe e com usuários do CAPS ad que dificultam na adesão do indivíduo ao tratamento no serviço.

b) Investigar quais são os motivos que levam as pessoas a romperem com o acompanhamento psicossocial, e como o CAPS ad atua enquanto um local pelo qual elas passam, mas não permanecem. 

Métodos 



\section{MÉTODOS}

\subsection{Delineamento}

Este estudo se caracteriza como uma pesquisa qualitativa experiencial, realista, entretanto crítica, já que irá considerar a reflexividade. Segundo a Organização Mundial de Saúde (OMS, 2019) a pesquisa qualitativa busca explorar e compreender as necessidades, valores, percepções e as experiências vivenciadas pelo mundo, incluindo desde aspectos de saúde ou doença, como também a sociedade e seus processos sociais e políticos. A OMS afirma que este tipo de informação é fundamental para melhorar a compreensão de como as pessoas percebem as intervenções em saúde, como também se faz essencial para entender os fatores que influenciam a implementação de políticas e de intervenções nesse contexto, se fazendo fundamental a participação e interação direta da sociedade civil. Willig (2001) reforça que as pesquisas qualitativas estão interessadas em conhecer como as pessoas dão sentido para o mundo e como experienciam eventos. Para a autora, os pesquisadores qualitativistas buscam entender "como é" experienciar uma condição particular e como as pessoas lidam com certas situações. Afirma que a pesquisa qualitativa se preocupa com a qualidade e textura da experiência, ao invés de relações de causa e efeito, ou seja, o objetivo da pesquisa qualitativa é descrever ou até explicar eventos, mas nunca os predizer.

Bogdan e Biklen (1998) assemelham-se ao reforçar que os pesquisadores qualitativistas visam compreender a fundo como as pessoas vivenciam suas experiências e como elas são representadas em suas vidas. Eles consideram que o significado é a ideia chave para a pesquisa, e referem que o pesquisador qualitativista não busca listar e determinar os comportamentos e nem correlacionar quantitativamente eventos vividos, mas sim se aprofundar no significado dessas experiências. Braun e Clarke (2014) elucidam que a pesquisa qualitativa experiencial valida os significados, visões, experiências e ou práticas expressadas por meio dos dados, em que as interpretações dos participantes são priorizadas. As autoras reforçam que a pesquisa experiencial é motivada pelo desejo de conhecer como o mundo é vivenciado pelas pessoas, e quais são os significados que elas atribuem a todas essas experiências. A pesquisa se constitui como o processo que coleta e organiza todas essas informações, e a linguagem o instrumento que as acessa. 
O referencial teórico-metodológico adotado é o realismo crítico, que ontologicamente considera que há uma realidade, entretanto, epistemologicamente compreende que esta só pode ser acessada de modo parcial pelo pesquisador, já que é socialmente localizada e influenciada pela cultura, linguagem e interesses políticos (Madill, Jordan \& Shirley, 2000). A resposta que o realismo crítico nos fornece é que existe um mundo externo, independentemente da consciência humana, e ao mesmo tempo uma dimensão que inclui nosso conhecimento que é socialmente determinado sobre a realidade (Danermark, 2002). No entanto Braun e Clarke (2006) enfatizam que a pesquisa só terá qualidade se houver a presença da reflexividade durante todo o seu desenvolvimento, a qual se caracteriza enquanto processo de reflexão crítica sobre o conhecimento que está sendo produzido e sobre o papel do próprio pesquisador na produção desse conhecimento, o qual segundo a OMS (2019) expressa valores e crenças sobre o tema pesquisado, fornecendo um certo grau de transparência acerca da própria visão a respeito dos dados.

Por fim, no contexto da saúde, Turato (2005) destaca ser indispensável conhecer o significado que as pessoas dão ao adoecimento e a vida, pois este é estruturante para definir como organizarão o cotidiano e como cuidarão da própria saúde. O autor aponta que o estudo dos significados atribuídos aos fenômenos envolvidos nos processos saúde-doença e no tratamento, auxiliam a melhorar a qualidade da relação do profissional com os pacientes e familiares, a definir estratégias de intervenção mais efetivas e a melhorar a adesão do paciente ao tratamento.

\subsection{Local}

Esta pesquisa foi realizada por meio da busca ativa por usuários de álcool e outras drogas que iniciaram acompanhamento no CAPS ad de qualquer município do país, porém não aderiram ao tratamento e atualmente não apresentam vínculo com o serviço. As entrevistas foram realizadas presencialmente ou por meio de vídeo chamada quando o participante não residia no local em que a pesquisadora se encontrava. 


\subsection{Participantes}

Os participantes foram usuários de álcool e outras drogas que já passaram por algum Centro de Atenção Psicossocial de Álcool e outras Drogas em todo território nacional, mas não deram continuidade ao tratamento, rompendo com a proposta terapêutica de forma autônoma. Assim, os critérios de inclusão no estudo foram: ser maior de 18 anos; ter sido indicado por ter interrompido o tratamento no CAPS ad sem este estar previsto em seu PTS; e concordar em participar com a pesquisa.

Para alcançar os objetivos do estudo foram realizadas entrevistas com 15 pessoas, seis do sexo feminino e as demais do sexo masculino, com idade média de 36,73 anos (mín. = 26, máx. =49), em sua maioria com perfil associado à abstinência. Apenas três entrevistados relataram manter uso regular de maconha, um em uso de cocaína e dois em uso múltiplo de álcool, crack, cocaína e maconha, e 13 pessoas relataram terem vivenciado internações em suas trajetórias de tratamento, principalmente em Comunidades Terapêuticas. As 15 entrevistas relataram vivências em 14 CAPS ad de 13 cidades do estado de São Paulo, sendo elas: Bauru, Jaboticabal, Marília, Mauá, Monte Alto, Ourinhos, Praia Grande, Piracicaba, Ribeirão Preto, Ribeirão Pires, São Paulo, Sertãozinho e Votorantim. Na cidade de São Paulo há relatos de dois CAPS ad (Figura1).

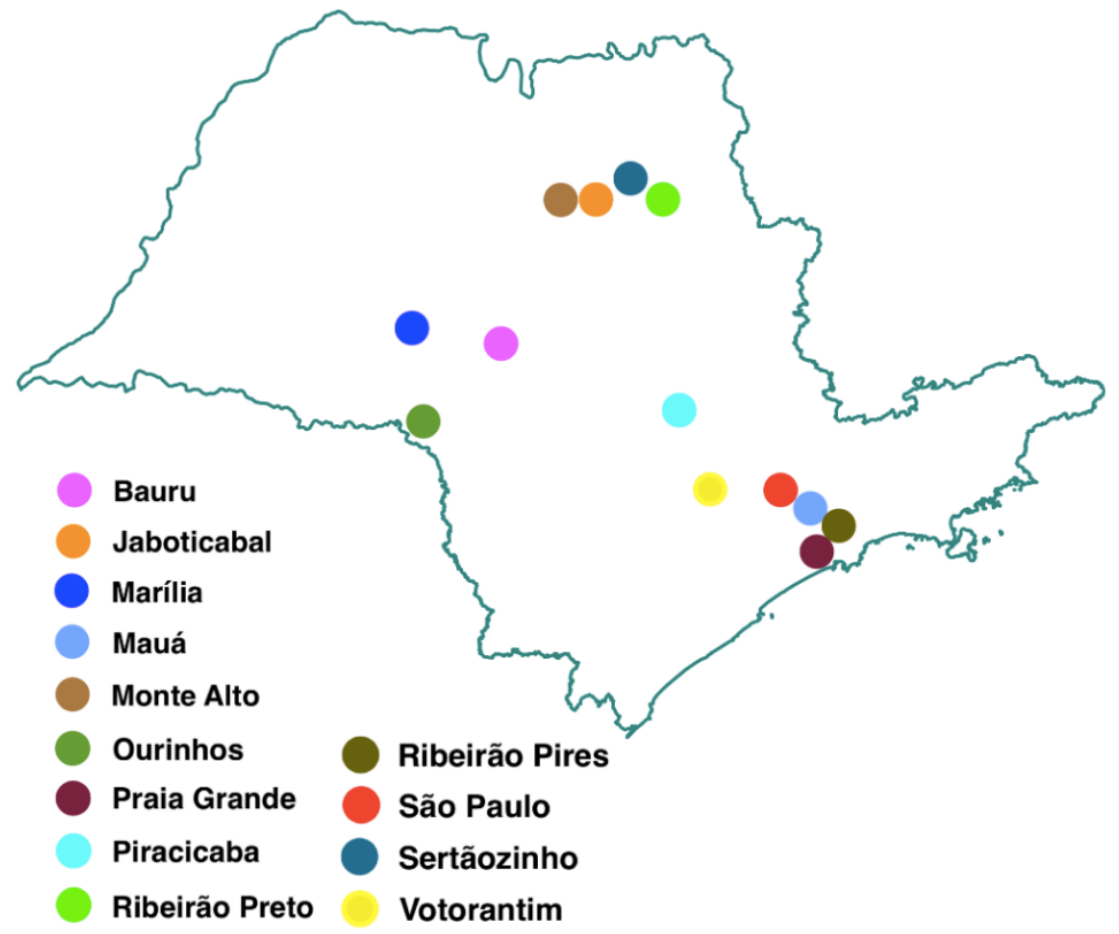

Figura 1 - Mapa do estado de São Paulo e os 13 municípios relatados pelos participantes da pesquisa. 
Tabela 2 - Características do consumo de drogas e da trajetória de tratamento dos participantes da pesquisa $(n=15)$.

\begin{tabular}{|c|c|c|c|c|c|c|}
\hline Participantes* & Idade & Substância(s) de uso & Perfil & Internação & CAPS ad & Tempo no CAPS \\
\hline César & 29 & $\begin{array}{l}\text { Álcool, cocaína, } \\
\text { maconha }\end{array}$ & Em uso de maconha & Comunidade Terapêutica & Ribeirão Preto/SP & 8 meses \\
\hline Vitor & 26 & $\begin{array}{l}\text { Álcool, cocaína, } \\
\text { maconha }\end{array}$ & Abstinência & Comunidade Terapêutica & Ribeirão Preto/SP & 6 meses \\
\hline Denis & 36 & Cocaína & Abstinência & Não & Piracicaba/SP & 5 meses \\
\hline Gustavo & 33 & Cocaína & Abstinência & $\begin{array}{l}\text { Hospital Psiquiátrico } \\
\text { Clínica Particular }\end{array}$ & Marília/SP & 15 dias \\
\hline Julio & 49 & Álcool & Abstinência & Comunidade Terapêutica & Votorantim/SP & 5 anos \\
\hline Livia & 44 & Álcool, cocaína, crack & Abstinência & $\begin{array}{l}\text { Comunidade Terapêtica } \\
\text { Enfermaria Psiquiátrica }\end{array}$ & $\begin{array}{c}\text { Ribeirão Pires/SP } \\
\text { Mauá/SP }\end{array}$ & $\begin{array}{l}4 \text { meses } \\
8 \text { meses }\end{array}$ \\
\hline Nivio & 38 & Crack & Abstinência & Comunidade Terapêutica & Ribeirão Preto/SP & 6 meses \\
\hline Ronaldo & 36 & Crcack, maconha & Em uso de maconha & $\begin{array}{l}\text { Hospital Psiquiátrico } \\
\text { Clínica Particular }\end{array}$ & Ribeirão Preto/SP & 4 meses \\
\hline Tatiana & 46 & $\begin{array}{l}\text { Álcool, cocaína, crack, } \\
\text { maconha }\end{array}$ & Abstinência & Comunidade Terapêutica & Ribeirão Preto/SP & 5 anos \\
\hline Valter & 36 & Álcool, crack, maconha & Em uso de maconha & $\begin{array}{l}\text { Comunidade Terapêutica } \\
\text { Hospital Psiquiátrico }\end{array}$ & $\begin{array}{l}\text { Praia Grande/SP } \\
\text { Ourinhos/SP }\end{array}$ & $\begin{array}{l}3 \text { meses } \\
3 \text { meses }\end{array}$ \\
\hline Bruno & 32 & Cocaína & $\begin{array}{l}\text { Em uso contínuo de } \\
\text { cocaína }\end{array}$ & Não & $\begin{array}{c}\text { São Paulo/SP } \\
\text { Sapopemba e } \\
\text { UNIFESP }\end{array}$ & $\begin{array}{l}2 \text { meses } \\
1 \text { mês }\end{array}$ \\
\hline Adriana & 31 & $\begin{array}{l}\text { Álcool, cocaína, crack, } \\
\text { maconha }\end{array}$ & $\begin{array}{l}\text { Em uso de álcool, } \\
\text { cocaína, crack e } \\
\text { maconha }\end{array}$ & $\begin{array}{c}\text { Hospital Psiquiátrico } \\
\text { Comunidade Terapêutica }\end{array}$ & Jaboticabal/SP & 1 ano \\
\hline Andrea & 39 & $\begin{array}{l}\text { Álcool, cocaína, crack, } \\
\text { maconha }\end{array}$ & $\begin{array}{l}\text { Em uso de álcool, } \\
\text { cocaína, crack e } \\
\text { maconha }\end{array}$ & $\begin{array}{c}\text { Casa de Passagem } \\
\text { Comunidade Terapêutica }\end{array}$ & Bauru/SP & $\begin{array}{l}\approx 10 \text { anos } \\
\text { (idas e vindas) }\end{array}$ \\
\hline Patricia & 35 & Álcool, cocaína & Abstinência & Comunidade Terapêutica & Sertãozinho/SP & $\begin{array}{c}1 \text { dia } \\
\text { (acolhimento incial) }\end{array}$ \\
\hline Rose & 41 & Álcool & Abstinência & Comunidade Terapêutica & Monte Alto/SP & 1 ano \\
\hline
\end{tabular}

*Nomes fictícios.

Esse número foi estabelecido por meio do critério do fechamento amostral por saturação teórica, o qual é frequentemente utilizado em áreas da saúde para definir o número de participantes de pesquisas. Segundo Fontanella, Ricas e Turato (2008), a saturação teórica dos dados é definida com a suspensão de novos participantes de uma pesquisa quando os dados já levantados passam a apresentar um padrão de repetição, ou seja, quando a obtenção de informações sobre determinado grupo ou categoria está saturada, e todas as informações pertinentes levantadas começam a se repetir. Para que este critério possa ser considerado, a pré-análise deve se iniciar logo após a primeira entrevista, com o objetivo de pré-categorização dos relatos e definição do tamanho amostral. 
Os participantes foram selecionados a partir da abordagem "bola de neve" no qual um conjunto inicial de participantes da pesquisa indicam potenciais sujeitos que também indicam outro grupo de pessoas que correspondem as necessidades do estudo, e assim sucessivamente (Bertaux, 1981) até que se alcance a amostragem por saturação. A pesquisadora utilizou de sua rede de contatos profissional e pessoal para identificar os primeiros participantes e solicitou a estes que indicassem outras pessoas com as mesmas características. Quando ocorreu a interrupção do processo de busca via entrevistados, a pesquisadora reativou a própria rede para retomar a "bola de neve". Segundo Heckathorn, (2011) essa abordagem é útil para localizar populações ocultas, estigmatizadas ou grupos de difícil alcance, como por exemplo, usuário de drogas.

Tabela 3 - Dados sociodemográficos dos participantes da pesquisa $(n=15)$.

\begin{tabular}{|c|c|c|c|c|c|c|}
\hline Participantes* & Idade & Escolaridade & Profissão & Renda familiar & $\begin{array}{l}\text { Pessoa responsável } \\
\text { pela renda familiar }\end{array}$ & Estado civil \\
\hline Vitor & 29 & $\begin{array}{l}\text { Ensino médio } \\
\text { completo }\end{array}$ & Vendedor & R\$998,00 & Entrevistado & Solteiro \\
\hline César & 26 & $\begin{array}{l}\text { Ensino médio } \\
\text { completo }\end{array}$ & $\begin{array}{c}\text { Vendedor } \\
\text { (desempregado) }\end{array}$ & Sem renda & $\begin{array}{l}\text { Dependente do } \\
\text { auxílio financeiro dos } \\
\text { pais }\end{array}$ & Solteiro \\
\hline Denis & 36 & Superior completo & $\begin{array}{c}\text { Jornalista } \\
\text { (desempregado) }\end{array}$ & Sem renda & $\begin{array}{l}\text { Dependente do } \\
\text { auxílio financeiro dos } \\
\text { pais e do irmão }\end{array}$ & Solteiro \\
\hline Gustavo & 33 & Superior incompleto & $\begin{array}{l}\text { Estudante de } \\
\text { medicina }\end{array}$ & $\mathrm{R} \$ 6.000,00$ & Marido & Casado \\
\hline Julio & 49 & $\begin{array}{l}\text { Ensino médio } \\
\text { completo }\end{array}$ & Aposentado & $\mathrm{R} \$ 1.600,00$ & Entrevistado & Divorciado \\
\hline Nivio & 44 & $\begin{array}{l}\text { Ensino superior } \\
\text { incompleto }\end{array}$ & Empresário & $\mathrm{R} \$ 10.000,00$ & Entrevistado e esposa & Casado \\
\hline Livia & 38 & $\begin{array}{l}\text { Ensino médio } \\
\text { completo }\end{array}$ & Manicure & $\mathrm{R} \$ 1.500,00$ & Entrevistada & Casada \\
\hline Ronaldo & 36 & Superior completo & $\begin{array}{l}\text { Ciências contábeis } \\
\text { (desempregado) }\end{array}$ & $\mathrm{R} \$ 8.000,00$ & Pai do entrevistado & Solteiro \\
\hline Tatiana & 46 & $\begin{array}{l}\text { Ensino médio } \\
\text { completo }\end{array}$ & Faxineira & $R \$ 340,00$ & Entrevistada & Solteira \\
\hline Valter & 36 & $\begin{array}{l}\text { Ensino médio } \\
\text { completo }\end{array}$ & $\begin{array}{c}\text { Instrutor de } \\
\text { autoescola } \\
\text { (desempregado) }\end{array}$ & Não informou & $\begin{array}{l}\text { Dependente da } \\
\text { aposentadoria da } \\
\text { esposa }\end{array}$ & Casado \\
\hline Bruno & 32 & $\begin{array}{l}\text { Pós-graduação } \\
\text { completa }\end{array}$ & Pesquisador & $\mathrm{R} \$ 3.150,00$ & Entrevistado & Solteiro \\
\hline Patricia & 31 & $\begin{array}{l}\text { Ensino médio } \\
\text { incompleto }\end{array}$ & $\begin{array}{c}\text { Ajudante geral } \\
\text { (desempregado) }\end{array}$ & $\mathrm{R} \$ 1.587,00$ & Pensão alimentícia & Divorciada \\
\hline Rose & 39 & $\begin{array}{l}\text { Ensino médio } \\
\text { completo }\end{array}$ & $\begin{array}{c}\text { Auxiliar } \\
\text { administrativo } \\
\text { (sem registro) }\end{array}$ & Não informou & Marido & Casada \\
\hline Adriana & 35 & $\begin{array}{l}\text { Ensino fundamental } \\
\text { completo }\end{array}$ & $\begin{array}{l}\text { Serviços gerais } \\
\text { (desempregada) }\end{array}$ & Sem renda & $\begin{array}{l}\text { Pleiteando Bolsa } \\
\text { Família }\end{array}$ & Divorciada \\
\hline Andrea & 41 & $\begin{array}{l}\text { Ensino médio } \\
\text { incompleto }\end{array}$ & Do lar & $\mathrm{R} \$ 91,00$ & $\begin{array}{l}\text { Beneficio social } \\
\text { Bolsa Família }\end{array}$ & Casada \\
\hline
\end{tabular}

*Nomes fictícios 
Vale ressaltar que a bola de neve foi interrompida constantemente, havendo necessidade que a pesquisadora reativasse sua rede frequentemente, e diante dos contatos profissionais se fez presente de forma recorrente uma fala realizada por algumas pessoas que se enquadram enquanto figuras técnicas de CAPS ad: que o único vínculo estabelecido com usuários de drogas que já haviam frequentado algum CAPS ad ocorreu apenas por intermédio do equipamento em que atuavam, dentro de um contexto exclusivamente profissional, não havendo possibilidade de indicar possíveis participantes para a pesquisa pois se tratava de informações vinculadas estritamente ao ambiente terapêutico, havendo a necessidade de uma autorização formal junto ao comitê de ética e da secretaria de saúde do município pertencente. Essa fala indagou a pesquisadora acerca do modelo de relação terapêutica estabelecida por meio destes profissionais, e do provável distanciamento social diante do que compreendem por pessoas que frequentam CAPS ad e que fazem uso problemático de drogas, como se estes não transitassem por entre os contextos comumente acessados por esses profissionais em questão. Além também de refletir sobre o anonimato e exclusão que essas pessoas ainda se encontram ao não serem identificadas e acessadas com facilidade e naturalidade, evidenciando um contexto social ainda presente de exclusão, segregação, e de posturas e discursos moralistas.

No entanto, a busca por participantes possibilitou uma vivência extremamente dinâmica e saudosista à pesquisadora, a qual reativou e reviveu sua própria trajetória profissional com intuito de encontrar sujeitos que pudessem contribuir com o estudo, instituindo um movimento generoso entre figuras até então desconhecidas e que se dispuseram ativamente para que os dados fossem alcançados. Para atingir o objetivo apresentado percorreu-se um percurso que envolveu contato com aproximadamente 60 pessoas entre figuras chaves que indicavam possíveis participantes e os participantes finais.

\subsection{Instrumento}

Para realizar a coleta de dados foi aplicada uma entrevista semiestruturada (APÊNDICE A). Braun e Clarke (2014) definem entrevista como uma conversa profissional que tem como objetivo obter informações sobre as vivências e percepções 
do entrevistado a partir da linguagem e concepções utilizadas pelo mesmo, baseados nos tópicos determinados pelo entrevistador.

A entrevista semiestruturada é predominantemente utilizada em pesquisas qualitativas. É um instrumento preparado previamente com tópicos estabelecidos pelo pesquisador que irão abordar um tema específico, porém, durante sua aplicação, ela não limita a participação e interação do entrevistado, possibilitando a intervenção e o surgimento de novas questões não antecipadas, sendo flexível e responsiva (Braun \& Clark, 2014). O entrevistador deve acompanhar o progresso e ritmo da entrevista, correspondendo a questões imprevistas e realizando perguntas espontâneas e não planejadas.

Considera-se que as perguntas abertas na entrevista semiestruturada possibilitam respostas detalhadas e encorajam o entrevistado a se aprofundar nas questões abordadas, possibilitando absorver a variedade e a diversidade de respostas a partir das próprias palavras do participante. O entrevistador desempenha um papel ativo na entrevista, produzindo o significado da narrativa em uma relação de interação e cooperação com o entrevistado. Não é possível nem desejável tentar minimizar o papel do entrevistador, o mesmo deve refletir sobre como suas práticas e valores podem ter moldado os dados produzidos (Braun \& Clark, 2014).

A entrevista semiestruturada abordou seis eixos temáticos: a) Identificação dos participantes; b) Início e padrão de consumo de substância; c) O percurso pela busca de ajuda antes de chegar ao CAPS ad; d) A busca pelo CAPS ad e a sua vivência; e) Características das relações com a equipe e com usuários do equipamento que dificultaram na adesão do indivíduo à proposta terapêutica; f) A trajetória de cuidado pós CAPS ad.

\subsection{Coleta de dados}

A coleta de dados foi realizada durante 11 meses, entre maio de 2018 a abril de 2019. As entrevistas foram realizadas presencialmente, ou por meio de vídeo chamada quando a pessoa não se encontrava no mesmo local que a pesquisadora.

Inicialmente, a pesquisadora identificou uma pessoa chave que pudesse indicar o primeiro participante da pesquisa, e por meio desta solicitou informações para contato, 
em seguida foi realizado contato telefônico com intuito de explicar as características e objetivos do estudo, e averiguar a disponibilidade e interesse do mesmo em participar. Em seguida, foi agendada uma entrevista presencial, ou por meio de vídeo chamada quando o entrevistado não se encontrava no mesmo local que a pesquisadora. Em data, horário e local pré-estabelecidos à pesquisadora leu novamente os objetivos do estudo, em que explicou a necessidade da gravação de áudio da entrevista, os direitos do entrevistado e realizou a leitura do Termo de Consentimento Livre e Esclarecido (TCLE) (APÊNDICE B). Ao concordar em conceder a entrevista e com a gravação desta, o participante foi convidado a assinar o TCLE e a preencher a ficha de identificação e de dados sociodemográficos, com intuito de identificar o entrevistado e seu nível socioeconômico (APÊNDICE A). Quando o entrevistado não se encontrava fisicamente no mesmo espaço que a entrevistadora, os documentos foram enviados por e-mail e retornados preenchidos e digitalizados pelo mesmo meio de comunicação. Ao final, todos os entrevistados foram questionados se conheciam alguma outra pessoa que havia passado pela mesma experiência de não aderir ao tratamento em CAPS ad. Quando positiva a resposta, solicitou-se as informações necessárias para entrar em contato com o possível participante, no entanto, quando negativa, retomou-se a rede de contato da própria pesquisadora como apontado anteriormente.

\subsection{Análise dos dados}

Foi realizada a análise temática, uma técnica proposta por Braun e Clarke (2014, 2006) para identificar, analisar e relatar padrões (temas) encontrados em dados qualitativos. Segundo as autoras, os estudos qualitativos são diversos, complexos e matizados, e a análise temática deve ser vista como um método fundamental para análise qualitativa. Para elas, um dos benefícios da análise temática é sua flexibilidade, a qual por meio da liberdade teórica fornece uma ferramenta de pesquisa flexível, possibilitando uma coletada de dados rica e detalhada. Reforçam que o método contribui tanto para refletir a realidade como quanto para desfazer ou desvendar a superfície da "realidade", possibilitando uma análise mais acessível, não se restringido a um conhecimento teórico e tecnológico detalhado.

A análise temática envolve a pesquisa em um conjunto de dados para encontrar padrões repetidos de significados. A forma exata e o produto de análise temática 
variam, e é importante que as questões referidas sejam consideradas antes e durante as análises temáticas. Trata-se de uma busca por temas que se tornem importantes para descrever um fenômeno, que se baseia em um processo conduzido em seis fases que serão descritos a seguir:

(1) Inicialmente foi realizada a familiarização com os dados coletados por meio da transcrição na íntegra das 15 entrevistas, contabilizando 283 páginas das 14 horas e 35 minutos de áudio, e em seguida realizou-se leitura ativa de todo o material em busca de significados e padrões. (2) Por conseguinte, foram produzidos códigos iniciais a partir da identificação de características que estão relacionadas aos objetivos da pesquisa e do fenômeno analisado, organizando-os em grupos significativos. Para isto foram utilizadas três colunas, a primeira contendo a entrevista na íntegra, a segunda um detalhamento identificando os objetivos do estudo e a terceira contendo os códigos organizados em possíveis temas iniciais. (3) Durante o processo de codificação, houve duas reuniões entre a pesquisadora e sua orientadora para leitura das entrevistas e códigos. (4) Na quarta fase realizou-se a revisão e refinação dos temas, buscando conhecer como estes se relacionavam com os códigos iniciais e com todo o conjunto de dados. Estes foram apresentados em duas reuniões com oito pesquisadores da área de drogas e da saúde pública. Braun e Clarke (2019) apontam a importância da inclusão de diferentes especialistas no processo de análise, tornando-o colaborativo e permitindo que a leitura destes se amplie, buscando-se diferentes nuances e contribuições para o campo. (5) Em seguida definiu-se e nomeou-se os temas que aqui serão apresentados, gerando um mapa temático como produto. (6) Por fim, produziu-se o relato por meio da seleção dos extratos de dados que ilustrem a prevalência do tema e da discussão dos resultados com a literatura da área.

Importante pontuar que este trabalho também seguiu os Critérios Consolidados para Relatar Pesquisa Qualitativa (COREQ checklist), o qual se constitui em uma lista de verificação à itens específicos para relatar estudos qualitativos, a fim de auxiliar os pesquisadores a indicar e expor aspectos importantes do tema estudado, cobrindo de forma abrangente o delineamento do estudo, e contribuindo para o reconhecimento e qualificação do mesmo (Tong, Sainsbury \& Craig, 2007). 


\subsection{Considerações éticas}

Este projeto foi aprovado pelo Comitê de Ética em Pesquisa da Faculdade de Filosofia, Ciências e Letras de Ribeirão Preto - USP. Sua aplicação seguiu os critérios éticos da Resolução n. ${ }^{\circ} 466$ de 12 de Dezembro de 2012, segundo a qual os participantes devem ser informados quanto aos procedimentos e objetivos da pesquisa, sendo livre sua decisão em participar do estudo, sempre garantindo o anonimato dos participantes, a confidencialidade, privacidade e não-estigmatização (Brasil, 2012), dessa forma todos os nomes foram alterados a fim de assegurar o sigilo e proteção. Foi realizada a leitura do Termo de Consentimento Livre e Esclarecido (TCLE) para todos os entrevistados, inclusive para os que se encontravam em outra cidade, realizando-se a leitura e a entrevista via chamada de vídeo, com envio de documentação e recebimento por e-mail do documento digitalizado. Considera-se que a pesquisa poderá trazer elementos que auxiliem na melhora do cuidado oferecido pelo SUS à usuários e álcool e outras drogas. 
Manuscritos 

4. DIFICULDADES PARA ADESÃO AO TRATAMENTO EM CENTRO DE ATENČ̃O PSICOSSOCIAL ÁLCOOL E OUTRAS DROGAS: RELACIONAMENTOS NO CAPS AD E CAPS AD ENQUANTO LOCAL DE PASSAGEM

Neste capítulo será descrita a relação entre os dois manuscritos que constituem os resultados desta dissertação. A partir da análise dos dados foram estabelecidos dois temas abrangentes que indicam os dados encontrados por meio da coleta realizada e que estão relacionados ao tema geral da pesquisa. Para apresentação e visualização destas informações elaborou-se um mapa temático, ferramenta utilizada pela análise temática que tem por objetivo conceitualizar de forma abrangente os padrões dos dados e as relações entre eles, indicando seus temas e subtemas (Souza, 2019). A seguir: 


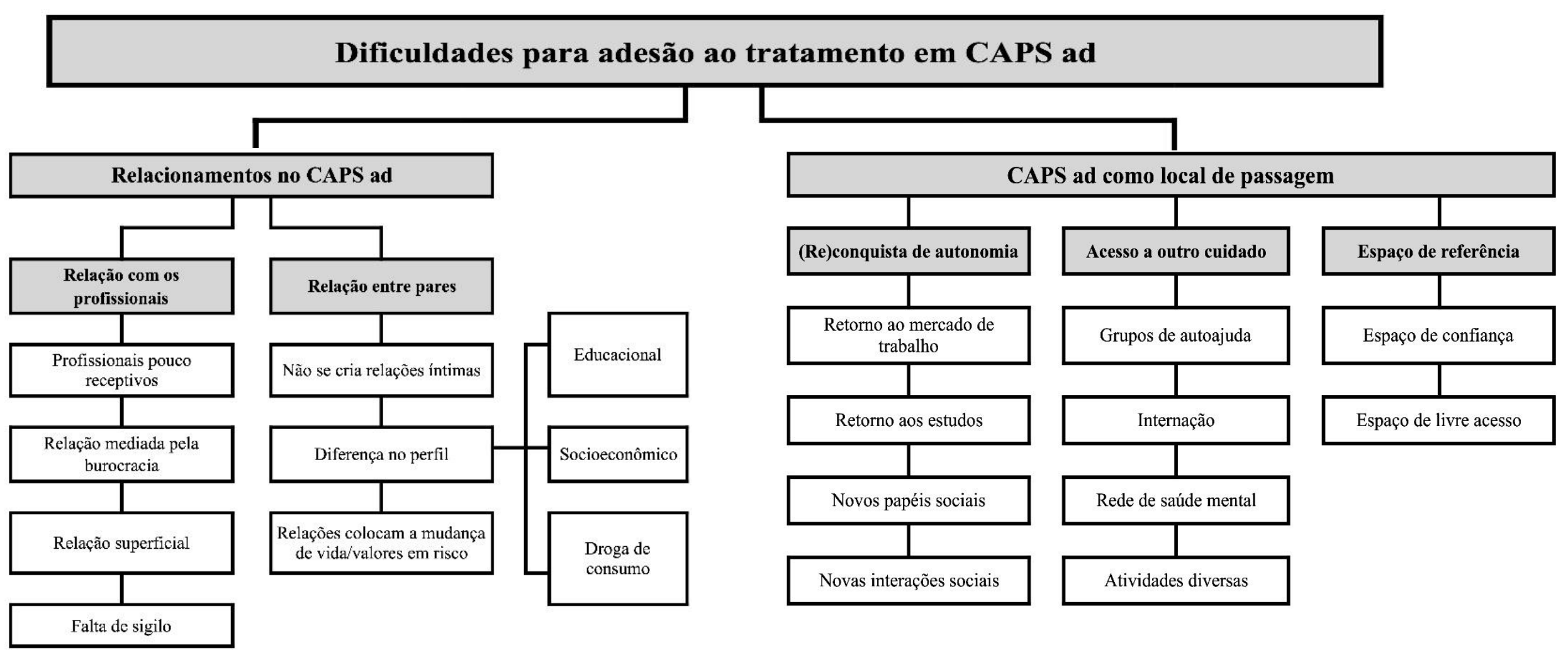

Figura 2 - Mapa temático que indica o tema principal, os dois temas abrangentes e os subtemas estabelecidos pela análise de dados da pesquisa. 
Os dois temas abrangentes indicados pela análise dos dados: relacionamentos no CAPS ad, e CAPS ad como local de passagem; foram explorados de forma ampliada por meio de dois manuscritos que foram submetidos para periódicos científicos.

O primeiro manuscrito "Relações interpessoais no tratamento do usuário de drogas como dificultador à adesão" foi desenvolvido diante da necessidade de explorar as relações interpessoais estabelecidas e vivenciadas por seus usuários dentro do contexto terapêutico, e que se constituíram enquanto critérios que dificultaram à adesão ao tratamento proposto pelo equipamento psicossocial. Tanto características das relações com a equipe multiprofissional, como também com seus pares, se mostraram deficientes diante dos critérios de humanização, otimização e espaço identitário, se fazendo necessário maior investimento e atenção para as práticas de cuidado. O segundo manuscrito, "CAPS ad como local de passagem para o usuário de drogas: compreendendo o processo de ruptura com o tratamento" explora a perspectiva do que se entende por adesão à terapêutica, propondo um novo olhar sobre o processo de permanência e de saída do equipamento de atendimento, pois ao analisar os dados por meio das narrativas dos participantes da pesquisa, constatou-se que os mesmos identificam o papel do espaço terapêutico de forma dinâmica, e não em um processo linear com início, meio e fim, mas sim como algo passageiro dentro de um contexto ampliado de vida.

Ambos os manuscritos exploram questões que afetam o processo de adesão ao CAPS ad na perspectiva da pessoa que buscou atendimento no local, primeiro discutindo sobre como se estabelece o ambiente terapêutico a partir das relações interpessoais e institucionais, e como estas podem comprometer e afetar a continuidade do processo do cuidado, para em seguida apresentar como se desenvolve o papel do equipamento diante do movimento itinerante da própria pessoa que faz uso problemático de drogas e da sua busca por tratamento, impondo um ritmo flutuante ao próprio equipamento de atendimento. 

Discussão 



\section{DISCUSSÃO}

O surgimento do Centro de Atenção Psicossocial Álcool e outras Drogas tem como objetivo romper com a lógica manicomial de internação e isolamento das pessoas que fazem uso problemático de álcool e outras drogas, propondo a abordagem psicossocial territorial como método de cuidado, na qual o projeto terapêutico deve se pautar nos aspectos de cidadania, em que a autonomia e o protagonismo da pessoa sejam fomentados de forma concreta no cotidiano de tratamento, devendo o sujeito ser participante ativo de todo o processo (Delfini et al, 2009).

A partir desta nova proposta de cuidado também se fez necessário uma novo olhar para a forma como as relações são estabelecidas no ambiente terapêutico, no qual orienta-se que o mesmo se desenvolva de forma disponível, em que a escuta e o diálogo se façam de forma empática e acolhedora, em uma dinâmica simétrica de interação, em que encontros intersubjetivos sejam rotina na atenção psicossocial (Martines \& Machado, 2010), pois como afirmam Nunes, Ottoni, Moraes Neto e Santana (2008): “as relações interpessoais e interações sociais são compreendidas como a base do existir humano e antecedem as técnicas terapêuticas inscrevendo-se na dimensão cidadã e política do cuidado".

No entanto, no cenário apontado, nota-se ainda presente no processo terapêutico, práticas profissionais insensibilizadas e aproximadas do fazer técnico, afirmando a dificuldade de se desfazer a fronteira entre o cuidado biológico altamente burocratizado, e o cuidado tido como sensível (Matumoto, 2003), reforçando segundo Martines e Machado (2010) “o sujeito-objeto, direcionada à doença", limitando a possibilidade de produção subjetiva, e consequentemente de interação e vinculação com a proposta terapêutica e equipe multiprofissional, dificultando a adesão ao CAPS ad.

Desde a porta de entrada as relações começam a se estabelecer no ambiente de cuidado, e a forma como essa atividade se desenvolve afeta a concepção acerca do que a abordagem psicossocial tem para ofertar. Ao se deparar com uma recepção burocrática amplia-se o nível de exigência para que a pessoa usuária de drogas consiga acessar o contexto de cuidado, reforçando um conceito de barreira de acesso que implica na 
compreensão equivocada acerca do acolhimento, pratica a qual se institui enquanto uma postura ética que orienta todo o Sistema Único de Saúde (SUS) (Lisbôa, Brêda \& de Albuquerque, 2014).

Como apontado pela pesquisa, tanto procedimentos tecnicistas como posturas pouco acolhedoras ainda se fazem presentes no primeiro contato da população usuária de drogas com o equipamento de saúde, afetando significativamente a subjetivação da pessoa diante do valor que a mesma aparenta ter para a instituição, internalizando um sentimento de menos valia, contribuindo para o reconhecimento do CAPS ad enquanto um serviço engessado, em que os protocolos antecedem o cuidado. Com essa dinâmica, fere-se também um dos principais manejos que auxiliam para maior adesão à terapêutica, o acolhimento imediato, pois uma característica substancial do público entrevistado é a flutuação de motivação, a qual quando se faz presente precisa ser acolhida e incentivada de forma eficiente e objetiva, a fim de possibilitar que o interesse pelo cuidado permaneça de forma longitudinal e resulte no vínculo com o equipamento e suas ramificações (Sales \& Silva, 2017).

Porém, mesmo quando o usuário consegue furar essa barreira de acesso inicial motivado pela necessidade de um acompanhamento terapêutico que seja socioeconomicamente disponível, outras práticas colocam em risco o vínculo e promovem o distanciamento da pessoa para com o espaço e com a proposta de cuidado. Posturas superficiais e manejos clínicos de baixo embasamento técnico não possibilitam o desenvolvimento de uma relação terapêutica segura e acolhedora entre usuário equipe - serviço, características fundamentais para a promoção da saúde mental e do cuidado integral da pessoa, pois como apontam Jorge et al (2011): "acolhimento e vínculo são decisivos na relação de cuidado entre o trabalhador de saúde mental e o usuário."

Dessa forma, a capacitação da equipe multiprofissional se mostra fundamental, sendo reconhecida a necessidade de uma gestão presente, que estimule e guie processos de trabalho adequados e fundamentais ao contexto de CAPS, indicando a importância de uma ação ampliada que domine diferentes saberes teórico, técnicos e políticos diante da complexidade que a área de álcool e outras drogas impõe. Silva e Knobloch (2016) afirmam que a formação dos trabalhadores que atendem a essa população precisa 
ocorrer de forma contínua e articulada ao cotidiano do serviço, pois o manejo necessário para se ofertar de forma adequada o cuidado da pessoa que faz uso problemático de álcool e outras drogas, extrapola o conhecimento acadêmico, sendo solicitado o saber adquirido empiricamente, incluindo a forma como os trabalhadores lidam com os sentidos e valores que constroem no decorrer da vida acerca da problemática, os quais podem comprometer significativamente a proposta do cuidado.

No entanto, pôde-se notar, que para além dos modelos de relações e interações estabelecidas com os profissionais do CAPS ad que dificultaram na adesão à terapêutica, também se fez marcante características dos relacionamentos entre os pares como fatores que afetaram na sensação de segurança e de pertencimento ao equipamento, promovendo afastamento da terapêutica.

Sabe-se que as relações interpessoais das pessoas que fazem uso problemático de drogas são afetadas negativamente em decorrência à dependência, havendo distanciamentos e rompimentos com figuras importantes da rede social destes sujeitos, fomentando o isolamento e o sentimento de solidão (de Souza, Kantorski \& Mielke, 2006). Ao buscar o CAPS ad para lidar com o fator que desencadeou tantas perdas, acredita-se que um novo círculo social seguro será estabelecido (de Sá Vieira et al, 2010), porém, o estudo aponta que essas relações só se fizeram possíveis em outros cenários de cuidado, sendo reconhecido grupos de autoajuda como espaços significativos para a constituição de novos vínculos tidos enquanto saudáveis (Lima \& Braga, 2012), características estas não identificadas e intermedidas pelo equipamento de saúde.

As interações pessoais estabelecidas por meio do CAPS ad foram reconhecidas enquanto contatos de risco para a retomada do consumo de substâncias, comprometendo a tão almejada mudança de valores e de vida, contribuindo para a identificação da rede social em questão como uma fonte de comportamentos danosos, se instituindo enquanto um vínculo de características negativas, promissor a comportamentos nocivos (PichonRivière, 1995), e consequentemente gerando o afastamento do espaço terapêutico.

Outra característica que afetou na adesão à proposta do cuidado, foi o sentimento de não identificação com o grupo de pessoas que frequentavam o CAPS ad devido a heterogeneidade que compõe o espaço, em que características 
socioeconômicas, educacionais e culturais se fizeram significativas para o sentimento de não pertencimento ao local. Sabe-se que equipamentos públicos de saúde devem ofertar por direito atendimento universal e igual a todo e qualquer cidadão, e em serviços direcionados ao público usuário de drogas, se faz frequente a participação de pessoas que se encontram em contexto de vulnerabilidade social, inclusive em situação de rua (Borysow \& Furtado, 2014).

A substância de preferência para consumo também foi apontada como um fator de diferenças significativas para a interação entre os demais usuários, sendo o crack indicado como a droga que promove maior distinção, tanto nos aspectos de cuidado como também sociais, havendo a necessidade segundo Xavier e Monteiro (2013) de intervenções específicas para esse público. Sabe-se que o uso problemático de crack, em sua maioria, tem sua origem em históricos de vida descendentes da exclusão social, e que seus impactos e problemas são ainda mais difíceis de serem tratados quando maior a precariedade nos aspectos econômicos e simbólicos de vida, e de relações interpessoais (Souza, 2016).

O CAPS ad tem importante papel para desmistificar e sensibilizar tanto a comunidade, como também seus próprios usuários sobre a importância do cuidado para toda e qualquer pessoa que faz uso problemático de drogas, e que tanto as trajetórias de vida, como as trajetórias de tratamento se constituem de forma singular, sendo o equipamento uma ferramenta que deve auxiliar na aproximação do território e no resgate da cidadania, em que as diferenças devem se fazer presentes no cotidiano do equipamento para efetivar de forma concreta os princípios do SUS diante da garantia universal por direito e acesso à saúde (Farias, 2017). Por tanto, ressalta-se a importância de fomentar espaços que desconstruam estigmas e preconceitos e que aproxime as pessoas tanto institucionalmente, como também territorialmente, possibilitando trocas efetivas e afetivas, pois como afirma Maffesoli (2005): "quanto mais o que se troca é minúsculo, mais essa troca favorece a proximidade" e consequentemente a recuperação.

E para se pensar na recuperação das pessoas que fazem uso problemático de drogas, necessita-se também compreender o papel que o CAPS ad desempenha na trajetória de cuidado destas. Sabe-se que há questionamentos acerca da efetividade da terapêutica ofertada pelo equipamento baseando-se no período que a pessoa permanece 
no tratamento e o momento que ela deixa de frequentar, no entanto, a partir das entrevistas realizadas notou-se que os entrevistados narraram a relação com o CAPS ad como um processo passageiro, em que outros momentos também significativos assumiram o espaço da intervenção psicossocial, inclusive como resultado da própria terapêutica.

O trabalho realizado no CAPS ad se distancia da lógica em que se tutela a pessoa que frequenta o equipamento de atendimento, pois objetiva sua emancipação e autonomia para que de fato o usuário possa se inserir em comunidade, em que novos vínculos e relações façam parte do repertório social, buscando-se outras formas de existir no mundo para além do uso de drogas (Farias, 2017), e o retorno ao mercado de trabalho foi uma das atividades identificadas que levou ao rompimento com a terapêutica, mas também que evidenciou o processo de reinserção social e a (re)conquista de autonomia como proposto pela própria intervenção psicossocial.

Neste mesmo movimento de independência e de uma rotina baseada em comportamentos autônomas, identificou-se também a retomada de antigos projetos como fatores que se sobrepuseram ao tratamento no CAPS ad, no qual atividades educacionais e novos cenários e papéis sociais se fizeram principais. Vale ressaltar que esses apontamentos vão de encontro aos objetivos que devem ser propostos pelo equipamento, o qual deve buscar minimizar dificuldades incapacitantes, e potencializar as singularidades de cada pessoa a fim de estimular uma vida com a qual se assume as próprias escolhas, em que o CAPS ad atue enquanto uma ferramenta que auxilia e possibilita mudanças, mas sem indicar com exatidão qual o momento de se iniciar e terminar todo o processo (Goldberg, 2001).

E diante desta trajetória itinerante do próprio usuário também foi observada a busca por outros cenários de cuidado como um fator resultante à passagem pelo equipamento de saúde mental, tanto devido à necessidade em continuar uma proposta terapêutica, como também da não identificação com a abordagem encontrada, buscando-se por outras estratégias como forma de cuidar do uso problemático de drogas, sem necessariamente vincular-se especificamente a uma única prática (Silva, 2018). Sabe-se que o CAPS ad está inserido no meio de uma ampla rede de iniciativas públicas, privadas e civil, a qual se desenvolve de forma dinâmica, contínua, e em 
grande parte conflitiva, intermediada por uma pluralidade metodológica e teórica (Silva \& Melo, 2000; Behring \& Boschetti, 2011), porém, mesmo o CAPS ad atuando dentro do modelo de portas abertas, na perspectiva da reabilitação psicossocial, a busca também continua grande por tratamentos restritivos e morais baseados na internação, e/ou na abstinência como única possibilidade de cuidado, inclusive em alguns contextos por intermédio do próprio equipamento (Schneider, 2015).

No entanto, nota-se que mesmo que o CAPS ad tenha se instituído por seus usuários enquanto um local de passagem, ele também foi reconhecido enquanto um espaço que possibilitou o acesso a uma rede intersetorial, com o qual também se ampliou o lugar de pertencimento no mundo, inclusive para voltar quando necessário, ou seja, os entrevistados deixaram a terapêutica porque sabiam que poderiam retornar a qualquer momento, reconhecendo a importância do equipamento diante da trajetória do cuidado, e principalmente, validando suas portas abertas para acolher todo tipo de demanda, mesmo que estas tenham que ser aprimoradas. 


\section{Considerações Finais}





\section{CONSIDERACÕES FINAIS}

Essa pesquisa buscou compreender quais as dificuldades que interferiram para adesão ao tratamento em Centro de Atenção Psicossocial Álcool e outras Drogas a partir da narrativa de pessoas que frequentaram o equipamento em algum momento de suas vidas, mas optaram em parar o processo terapêutico de forma autônoma. Importante ressaltar que todos os entrevistados foram ativados a partir de uma rede ampliada de pessoas que não se conheciam entre si, e que nenhum CAPS ad foi utilizado como intermédio para alcançar os participantes indicados, contribuindo significativamente para o acesso a um discurso mais neutro possível diante da instituição, e consequentemente ampliando o grau de complexidade para a descoberta de novos participantes e informações.

A partir da análise dos dados foi possível notar que as relações interpessoais estabelecidas no CAPS ad foram reconhecidas enquanto fatores que contribuíram significativamente para o rompimento com o a abordagem psicossocial, e mesmo que o equipamento tenha como premissa o cuidado humanizado baseado em relações simétricas por meio de uma postura acolhedora, ainda se fazem presentes e resistentes relações distanciadas intermediadas pelo tecnicismo, na qual a burocracia se sobressai diante de profissionais pouco receptivos, que evidenciam um possível descontentamento com o trabalho que realizam e as dificuldades que o ambiente provêm, inclusive demonstrando manejos que requerem maior embasamento teórico e prático, comprometendo a ética necessária para o bom funcionamento de qualquer ambiente terapêutico, e contribuindo para a fomentação de um sentimento de menos valia entre seus assistidos. Esses apontamentos escancaram a necessidade de processos formativos contínuos para profissionais de CAPS ad, os quais necessitam ter acesso de forma sistemática a um amplo repertório acerca da temática, e também sobre os princípios que legitimam e direcionam o Sistema Único de Saúde e todos os seus equipamentos de atendimento, para assim de fato ofertar um contexto de cuidado condizente com o que é determinado por direito a todo e qualquer cidadão.

Entretanto, além das relações nem tão bem estabelecidas com a equipe, as interações entre os pares também foram indicadas como fatores que interferiram para a 
adesão à proposta do cuidado, observou-se que os usuários do CAPS ad buscaram no equipamento de atendimento além de um espaço terapêutico, um ambiente relacional que possibilitasse interações aproximadas e seguras, visto que as relações sociais são as mais afetadas em decorrência ao uso problemático de drogas, no entanto, ao se depararem com relacionamentos que não se aprofundaram e não evoluíram para relações maiores e para fora do equipamento, o CAPS ad não se instituiu enquanto um espaço afetivo e de trocas saudáveis, ainda mais com o agravante de que essas mesmas pessoas também foram identificadas como um risco para as mudanças de valores e de vida que os entrevistados tanto buscavam. Foi frequente a identificação dos demais usuários do CAPS ad enquanto pessoas que não estavam comprometidas com o tratamento, principalmente quanto estas não se direcionavam para o padrão da abstinência, afetando significativamente a sensação de segurança que esperavam encontrar no contexto psicossocial. Aspectos socioeconômicos, educacionais, culturais e droga de preferência também foram referidos enquanto marcadores que afetaram para a sensação de não identificação e não pertencimento ao contexto.

O CAPS ad tem importante papel para a desconstrução de valores morais, estigmas e preconceitos que permeiam o usuário de drogas, tanto institucionalmente como também em comunidade, mas para isso é fundamental que o equipamento se aproxime e interaja com as figuras e espaços de referência que constituem o território subjetivo e concreto de seus atendidos, para possibilitar o desenvolvimento de um serviço que se adapte e interaja de forma dinâmica com a pluralidade inerente do contexto público, e principalmente das pessoas que fazem uso problemático de drogas, pois relacionamentos positivos, oportunidades significativas e envolvimento da comunidade são elementos fundamentais para o processo de recuperação, e cabe ao equipamento apoiar e incentivar ativamente as pessoas a utilizar oportunidades na comunidade, de acordo com seus valores, interesses e aspirações pessoais.

Contudo, esta pesquisa além de identificar as relações interpessoais como fatores que interferiram para o processo de continuidade da terapêutica, também foi observado que para além da adesão compreendida enquanto um processo linear com início, meio e fim, os entrevistados narraram uma trajetória de cuidado que se desenvolveu de forma passageira, identificando o CAPS ad como um local pelo qual passam quando necessitam, e saem quando assim também entendem ser necessário. Um dos 
apontamentos que indicou essa dinâmica, foi uma característica que se enquadra como objetivo da própria terapêutica, a (re)conquista de autonomia, com a qual alguns dos participantes informaram terem abandonado o tratamento no CAPS ad pois haviam retornado para o mercado de trabalho, e a rotina de cuidado do equipamento não se enquadrava mais no cotidiano, além também de outros projetos de vida preexistentes ao uso problemático de drogas, como também o desempenho de novos papéis sociais, todos foram identificados como fatores que se sobressaíram ao espaço terapêutico. Vale frisar que os entrevistados que se enquadraram em uma classe social de maior poder socioeconômico demonstraram maior fluidez para atingir a independência e otimizar o processo de reinserção social.

No entanto, a busca por outras abordagens de cuidado também intermediou a saída do CAPS ad, os entrevistados narraram que em suas trajetórias de tratamento para uso problemático de drogas ativaram diversas ferramentas disponíveis na rede, sendo o equipamento em questão um dos recursos utilizados, porém, ao não se identificarem e/ou considerarem necessário uma abordagem mais restritiva, deixaram de frequentar o espaço em busca de uma nova tentativa terapêutica, sendo identificada a passagem por outros equipamentos da Rede de Atenção Psicossocial (RAPS), com uma atenção maior para as internações em Comunidades Terapêuticas, além também de grupos de autoajuda e atividades diversas. Porém, mesmo com a interrupção do acompanhamento psicossocial, foi possível observar que os entrevistados identificaram o CAPS ad como um espaço de referência caso seja necessário retornar, e que inclusive o rompimento está associado a este sentimento de segurança de que há um lugar de portas abertas para recebe-los, e por mais que sejam identificadas necessidades de aprimoramento neste processo, o acesso ao CAPS ad se dá de forma livre.

Esse estudo traz contribuições para aprimorar os protocolos e práticas existentes nos CAPS ad, e principalmente para se pensar o quanto as relações interpessoais se fazem fundamentais ao caracterizar um espaço de cuidado, transcendendo o conhecimento teórico que embasa o cenário. Nota-se a necessidade de aperfeiçoar a dinâmica dos recursos humanos disponíveis nos equipamentos para que práticas individuais ou coletivas não comprometam uma postura de cuidado ética que deve ser centrada no sujeito, além também de promover maior aproximação do usuário para que de fato a construção do cuidado se dê de forma colaborativa, para que a trajetória 
terapêutica se desenvolva de forma identitária. Sendo assim, orienta-se que o CAPS ad amplie sua participação comunitária, requerendo de fato maior territorialização e consequentemente possibilitando maior acesso à espaços, cenários e grupos sociais que sejam significativos e simbólicos à seus assistidos, fomentando a participação social como ferramenta da abordagem psicossocial, haja vista que o objetivo do equipamento não deve se findar em suas paredes. Também evidencia a necessidade de reposicionar a compreensão acercar do que se entende por adesão ao CAPS ad, a qual não deve ser analisada única e exclusivamente como um fator quantitativo dentro de uma perspectiva linear, mas sim em um movimento dinâmico como requer as relações humanas e principalmente o perfil itinerante do próprio usuário de drogas, o qual não se vincula e adere unicamente a uma terapêutica. Reconhecer o CAPS ad enquanto um local de passagem para a pessoa que o acessa ressalta a importância das portas abertas para romper efetivamente com o paradigma manicomial, evidenciando a importância das relações democráticas para a consolidação do cuidado em liberdade, tanto concretamente como subjetivamente.

Neste sentido, novas pesquisas acerca da temática se fazem relevantes, havendo a necessidade de ampliar este estudo para outras regiões do país, a fim de analisar se fatores culturais interferem no desenvolvimento dos Centros de Atenção Psicossocial Álcool e outras Drogas, e nos processos de adesão de seus usuários, visto que um dos limites deste trabalho está relacionado ao fator regional, já que todos os entrevistados relataram vivências apenas no estado de São Paulo, classificada também como a unidade federativa mais rica do Brasil, sendo assim, se faz necessária a investigação de outros cenários culturais e realidades econômicas. Por fim, indica-se também a importância de analisar a concepção dos profissionais de CAPS ad acerca do que identificam na rotina do equipamento e de suas práticas cotidianas que consideram interferir na adesão de seus usuários, possibilitando assim um contraponto de vivências e percepções. 
Referências 



\section{REFERÊNCIAS}

Aberta. (2017). Portal da Secretaria Nacional de Políticas Sobre Drogas e Ministério da Justiça 2016-2017. Recuperado de: http://www.aberta.senad.gov.br/.

Alves, V. S. (2009). Modelos de atenção à saúde de usuários de álcool e outras drogas: discursos políticos, saberes e práticas. Cadernos de Saúde Pública, 25, 2309-2319.

Amarante P. (2003). A clínica e a Reforma Psiquiátrica. In: Amarante P, organizador. Archivos de Saúde Mental e Atenção Psicossocial Rio de Janeiro: NAU Editora; p. 45-66.

Amarante, P. D. C., \& Torre, E. H. G. (2001). Constituição de novas práticas no campo da Atenção Psicossocial: análise de dois projetos pioneiros na Reforma Psiquiátrica no Brasil. Saúde em Debate, v.25, n.58 p. 26-34.

Azevedo, D. M. D., \& Miranda, F. A. N. D. (2011). Oficinas terapêuticas como instrumento de reabilitação psicossocial: percepção de familiares. Escola Anna Nery, 15(2), 339-345.

Barbosa, G. C., Oliveira, M. A. F. D., Moreno, V., Padovani, C. R., Claro, H. G., \& Pinho, P. H. (2015). Satisfação de usuários num Centro de Atenção Psicossocial em álcool e outras drogas. Revista Portuguesa de Enfermagem de Saúde Mental, (14), 31-37.

Bastos, F. I. P. M., \& Bertoni, N. (2014). Pesquisa Nacional sobre o uso de crack: quem são os usuários de crack e/ou similares do Brasil? quantos são nas capitais brasileiras?.

Bogdan, R.C. and Biklen, S.K. (1998) Qualitative Research in Education: An Introduction to Theory and Methods, 3rd edn. Boston, MA: Allyn and Bacon.

Borysow, I. D. C., \& Furtado, J. P. (2014). Acesso, equidade e coesão social: avaliação de estratégias intersetoriais para a população em situação de rua. Revista da Escola de Enfermagem da USP, 48(6), 1069-1076.

Brasil, C. C. (1990). Lei $n^{\circ}$ 8.080, de 19 de setembro de 1990. Dispõe sobre as condições para a promoção, proteção e recuperação da saúde, a organização e o funcionamento dos serviços correspondentes e dá outras providências. Diário Oficial da união, 20. 
Brasil, C. (2001). Lei $\mathrm{n}^{\mathrm{o}}$ 10.216, de 6 de abril de 2001. Dispõe sobre a proteção e os direitos das pessoas portadoras de transtornos mentais e redireciona o modelo assistencial em saúde mental. Diário Oficial da União, (s2001).

Brazil. Ministério da Saúde. Secretaria Executiva. (2001). SUS princípios e conquistas. Ministério da Saúde.

Brasil, C., \& Reis, G. G. (2004). Ministério da Saúde. Secretaria de Atenção à Saúde. Departamento de Ações Programáticas Estratégicas. Saúde mental no SUS: Os Centros de Atenção Psicossocial: Brasília.

Behring, E. R., \& Boschetti, I. (2017). Política social: fundamentos e história. Cortez editora.

Bertachini, L. (2012). A comunicação terapêutica como fator de humanização da Atenção Primária. Mundo Saúde, 36(3), 507-20.

Bertaux, D. Biography and society: The life history approach in the social sciences. Beverly Hills, CA: Sage, 1981.

Borysow, I. D. C., \& Furtado, J. P. (2014). Acesso, equidade e coesão social: avaliação de estratégias intersetoriais para a população em situação de rua. Revista da Escola de Enfermagem da USP, 48(6), 1069-1076.

Braun, V., \& Clarke, V. (2006). Using thematic analysis in Psychology. Qualitative Research in Psychology, 3(2), pp. 77-101.

Braun, V., \& Clarke, V. (2014). Successful qualitative research: a practical guide for beginner. London: SAGE.

Braun, V., \& Clarke, V. (2019). Reflecting on Reflexive Thematic Analysis. Qualitative Research In Sport, Exercise And Health. 2019, VOL. 11, NO. 4, 589-597

Bezerra, E., \& Dimenstein, M. (2008). Os CAPS e o trabalho em rede: tecendo o apoio matricial na atenção básica. Psicologia: Ciência e Profissão, 28(3), 632-645. Recuperado de: https://dx.doi.org/10.1590/S1414-98932008000300015. 
Cardoso, R. M. M. (2006). Só por hoje: um estudo sobre Narcóticos Anônimos, estigma social e sociedade contemporânea. Orientador: Adriana Facina Gurgel do Amaral. Dissertação (Mestrado)-Universidade Federal Fluminense, Departamento de História.

Capistrano, F. C., Ferreira, A. C. Z., Silva, T. L., Kalinke, L. P., \& Maftum, M. A. (2013). Perfil sociodemográfico e clínico de dependentes químicos em tratamento: análise de prontuários. Escola Anna Nery Revista de Enfermagem, 17(2), 234-241.

Casares-López, J.M., González-Menéndez A., Festinger D.S., Fernández-García P., Fernández-Hermida J.R., Secades R., \& Matejkowski J. (2013). Predictors of retention in a drug-free unit/substance abuse treatment in prison. Int J Law Psychiatr. 36(3):264-72.

Casswell, S. (2000). A decade of community action research. Subst Use Misuse, 35:55-74.

Castro, M. M., \& Passos, S. R. L. (2005). Entrevista motivacional e escalas de motivação para tratamento em dependência de drogas. Archives of Clinical Psychiatry (São Paulo), $32(6), 330-335$.

Center for Substance Abuse Treatment. (1999). Enhancing motivation for change in substance abuse treatment.

Costa, P. H. A., Mota, D. C. B., Paiva, F. S., \& Ronzani, T. M. (2015). Desatando a trama das redes assistenciais sobre drogas: uma revisão narrativa da literatura. Ciência \& Saúde Coletiva, 20(2), 395-406. Recuperado de: https://dx.doi.org/10.1590/141381232015202.20682013 .

Costa, P. H. A. D., Ronzani, T. M., \& Colugnati, F. A. B. (2017). "No papel é bonito, mas na prática..." Análise sobre a rede de atenção aos usuários de drogas nas políticas e instrumentos normativos da área. Saúde e Sociedade, 26, 738-750.

Cunningham, J. A., \& Breslin, F. C. (2004). Only one in three people with alcohol abuse or dependence ever seek treatment. Addictive behaviors, 29(1), 221-223.

Damásio-Dutra, V. F., \& Oliveira, R. M. P. (2015). Revisão integrativa: as práticas territoriais de cuidado em saúde mental. Aquichan, 15(4), 529-540.

Danermark, B. (2002). Interdisciplinary research and critical realism the example of disability research. Alethia, 5(1), 56-64. 
da Silva Carvalho, J. E., Liotti, D. B. M., \& Lenzi, M. C. R. (2015). CAPS AD e Alcoólicos Anônimos: o processo de tratamento sob o ponto de vista dos usuários. Cadernos Brasileiros de Saúde Mental/Brazilian Journal of Mental Health, 7(16), 41-61.

de Andrade, A. T., de Sousa, M. L. T., \& Quinderé, P. H. D. (2013). Acolhimento no Centro de Atenção Psicossocial para álcool e outras drogas: concepções dos trabalhadores de saúde. Revista Pesquisas e Práticas Psicossociais, 8(2), 166-175.

Delfini, Patrícia Santos de Souza, Sato, Miki Takao, Antoneli, Patrícia de Paulo, \& Guimarães, Paulo Octávio da Silva. (2009). Parceria entre CAPS e PSF: o desafio da construção de um novo saber. Ciência \& Saúde Coletiva, 14(Suppl. 1), 1483-1492. https://doi.org/10.1590/S1413-81232009000800021

de Sá Vieira, J. K., Carvalho, R. N., de Azevedo, E. B., de Castro Silva, P. M., \& Filha, M. D. O. F. (2010). Concepção sobre drogas: relatos dos usuários do CAPS ad, de Campina Grande, PB. SMAD, Revista Electrónica en Salud Mental, Alcohol y Drogas, 6(2), 274295.

de Souza, J., Kantorski, L. P., \& Mielke, F. B. (2006). Vínculos e redes sociais de indivíduos dependentes de substâncias psicoativas sob tratamento em CAPS AD. SMAD, Revista Electrónica en Salud Mental, Alcohol y Drogas, 2(1), 0.

Diário Oficial da União (2019). Recuperado de: http://www.in.gov.br/materia//asset_publisher/Kujrw0TZC2Mb/content/id/71137357

Digiusto, E., \& Treloar, C. (2007). Equity of access to treatment, and barriers to treatment for illicit drug use in Australia. Addiction, 102(6), 958-969. doi:10.1111/j.13600443.2007.01842.x

Dimenstein, M., \& Bezerra, G. C. (2011). O fenômeno da reinternação: um desafio à Reforma Psiquiátrica. Observatório Nacional de Saúde Mental e Justiça Criminal, 16 (1), 417- 442. Recuperado de: http://pepsic.bvsalud.org/pdf/mental/v9n16/a07v9n16.pdf do Amaral, R. A., \& Rieth, C. E. (2015). Sigilo e integralidade no cuidado em saúde mental: desafios à atuação do psicólogo no Sistema Único de Saúde. Aletheia, (47-48). 
dos Santos Levy, V. L. (2016). Oficinas terapêuticas e produção de vínculo em CAPS AD. Cadernos Brasileiros de Saúde Mental/Brazilian Journal of Mental Health, 8(19), 97-106.

dos Santos Mangualde, A. A., Botelho, C. C., Soares, M. R., Costa, J. F., Junqueira, A. C. M., \& Vidal, C. E. L. (2013). Perfil epidemiológico dos pacientes atendidos em um Centro de Atenção Psicossocial. Mental, 10(19), 235-248.

Farias, I. D. D. (2017). Dádivas, afetos e trocas sociais no cotidiano de sujeitos permeados por vivências psicossociais em Pelotas-RS.

Ferreira, A. C. Z., Borba, L. D. O., Capistrano, F. C., Czarnobay, J., \& Maftum, M. A. (2015). Fatores que interferem na adesão ao tratamento de dependência química: percepção de profissionais de saúde. Revista Mineira de Enfermagem, 19(2), 150-164.

Ferreira, A. C. Z., Capistrano, F. C., Souza, E. B., Borba, L. O., Kalinke, L. P., \& Maftum, M. A. (2015). Motivações de dependentes químicos para o tratamento: percepção de familiares. Revista Brasileira de Enfermagem, 68(3), 474-481. Recuperado de: https://dx.doi.org/10.1590/0034-7167.2015680314i.

Ferreira, M. S. C., Pereira, M. A. O., \& Pereira Júnior, A. (2013). Auto-organização, autonomia e o cuidado em saúde mental. Simbio-Logias, 41-52.

Figueiredo, R., Feffermann, M., \& Adorno, R. (2017). Drogas \& Sociedade Contemporânea: perspectivas para além do proibicionismo. São Paulo: Instituto de Saúde.

Fikri-Benbrahim, N., García-Cárdenas, V., Sáez-Benito, L., Gastelurrutia, M. A., Faus M. P., Schneider, M. P., \& Aslani, P. (2009). Adherence: a review of education, research, practice and policy in Spain. Recuperado de: https://www.ncbi.nlm.nih.gov/pmc/articles/PMC4139043/

Fiore, M. (2005). A medicalização da questão do uso de drogas no Brasil: reflexões acerca de debates institucionais e jurídicos. In: Venâncio, r p \& Carneiro, H . Álcool e drogas na História do Brasil. São Paulo: Alameda; Belo Horizonte: Editora PUC Minas, p.257-290.

Fontanella, B. J. B., Ricas, J., \& Turato, E. R. (2008). Amostragem por saturação em pesquisas qualitativas em saúde: contribuições teóricas. Cadernos de saúde pública, 24, 17 27. 
Gearing, R. E., Townsend, L., Elkins, J., El-Bassel, N., \& Osterberg, L. (2014). Strategies to predict, measure, and improve psychosocial treatment adherence. Harvard review of psychiatry, 22(1), 31-45.

Giacomozzi, A. I. (2011). Representações sociais da droga e vulnerabilidade de usuários de CAPSad em relação às DST/HIV/AIDS. Estudos e Pesquisas em Psicologia, 11(3), 776795.

Goldberg, J. (2001). Reabilitação como processo-O centro de atenção psicossocial-CAPS. Reabilitação psicossocial no Brasil, 33-47.

Gonçalves, A. M.; Sena, R. R. (2001). A reforma psiquiátrica no brasil: contextualização e reflexos sobre o cuidado com o doente mental na família. Revista Latino-Americana Enfermagem, v. 9, n. 2, p. 48-55. Recuperado de: http://www.revistas.usp.br/rlae/article/viewFile/1551/1596

Guimarães, T. A., \& Rosa, L. C. S. (2019). A remanicomialização do cuidado em saúde mental no Brasil no período de 2010-2019: análise de uma conjuntura antirreformista. O Social em Questão, 22(44), 111-138.

Heckathorn, D. D. (2011). Comment: snowball versus respondent-driven sampling. Sociological Methodology, n.1, v.41, p. 355-366.

Holder, H.D. (1997). Alcohol use and a safe environment. Addiction. 92 Suppl 1:S117-20

Jorge, Maria Salete Bessa, Pinto, Diego Muniz, Quinderé, Paulo Henrique Dias, Pinto, Antonio Germane Alves, Sousa, Fernando Sérgio Pereira de, \& Cavalcante, Cinthia Mendonça. (2011). Promoção da Saúde Mental - Tecnologias do Cuidado: vínculo, acolhimento, co-responsabilização e autonomia. Ciência \& Saúde Coletiva, 16(7), 30513060. https://doi.org/10.1590/S1413-81232011000800005

Lacerda, C. D. B., \& Fuentes-Rojas, M. (2016). Significados e sentidos atribuídos ao Centro de Atenção Psicossocial Álcool e outras Drogas (CAPS AD) por seus usuários: um estudo de caso. Interface-Comunicação, Saúde, Educação, 21, 363-372.

Lemke, R. A., \& da Silva, R. A. N. (2010). A busca ativa como princípio político das práticas de cuidado no território. Estudos e Pesquisas em Psicologia, 10(1), 281-295. 
Lemke, R. A., \& Silva, R. A. N. D. (2011). Um estudo sobre a itinerância como estratégia de cuidado no contexto das políticas públicas de saúde no Brasil. Physis: Revista de Saúde Coletiva, 21(3), 979-1004.

Levy, V. L. S. (2016). Oficinas terapêuticas e produção de vínculo em caps ad. Cadernos Brasileiros de Saúde Mental . v. 8, n. 19.

Lima, F. A. F. (2009). Justiça Terapêutica: em busca de um novo paradigma. Tese de doutorado, Faculdade de Direito. Universidade de São Paulo, Brasil.

Lima, H. D. P., \& Braga, V. A. B. (2012). Grupo de autoajuda como modalidade de tratamento para pessoas com dependência de álcool. Texto \& Contexto-Enfermagem, 21(4), 887-895.

Lima, F. C., \& Schneider, R. D. (2013). Avaliação dos Centros De Atenção Psicossocial: Uma Revisão Integrativa Da Literatura Nacional. Revista Caminhos, On-line, “Humanidades", Rio do Sul, a. 4, n. 6, p. 39-64, abr./jun. 2013

Lisbôa, G. L. P., Brêda, M. Z., \& de Albuquerque, M. C. D. S. (2014). Concepções e práticas de acolhimento aos familiares na atenção psicossocial em álcool e outras drogas. Revista da Rede de Enfermagem do Nordeste, 15(2), 264-272.

Lovejoy M, Rosenblum A, Magura S, Foote J, Handelsman L, Stimmel B. Patients' perspective on the process of change in substance abuse treatment. J Subst Abuse Treat. 1995;12:269-282.

Machado, A. R., Modena, C. M., \& Luz, Z. M. P. D. (2019). O que pessoas que usam drogas buscam em serviços de saúde? Compreensões para além da abstinência. InterfaceComunicação, Saúde, Educação, 24, e190090.

Machado, A. R., \& Miranda, P. S. C. (2007). Fragmentos da história da atenção à saúde para usuários de álcool e outras drogas no Brasil: da Justiça à Saúde Pública. História, Ciências, Saúde-Manguinhos, 14(3), 801-821.

Madill, A.,Jordan, A., \& Shirley, C. (2000). Objectivity and reliability in qualitative analysis: realist, contextualist and radical contructionist epistemologies. Britsh Journal of 
Psychology, 91, 1-20. Maffesoli M. O mistério da conjunção: ensaios sobre comunicação, corpo e socialidade. Porto Alegre: Sulina; 2005.

Malvezzi, C. D., Gerhardinger, H. C., Santos, L. F. P., Toledo, V. P., \& Garcia, A. P. R. F. (2016). Adherence to treatment by the staff of a mental health service: an exploratory study. Online Brazilian Journal of Nursing, 15(2), 177-187.

Manfrê, M. M. (2015). Redes de atenção aos usuários de álcool e outras drogas: a visão dos trabalhadores e gestores de serviços de saúde mental de um município do Estado de São Paulo. Revista de Psicologia da UNESP, 14(1), 26-37.

Martines, W. R. V., \& Machado, A. L. (2010). Producción de cuidado y subjetividad. Revista brasileira de Enfermagem, 63(2), 328-333.

Matumoto, S. (2003). Encontros e desencontros entre trabalhadores e usuários na saúde em transformação: um ensaio cartográfico do acolhimento (Doctoral dissertation, Universidade de São Paulo).

Manual CAPS ad. Saúde Mental no SUS: Os Centros de Atenção Psicossocial. Brasília. (2004). Marzano, M. L. R., \& Sousa, C. A. C. D. (2004). O espaço social do CAPS como possibilitador de mudanças na vida do usuário. Texto \& Contexto-Enfermagem, 13(4), $577-584$.

Melo, M. C., \& Corradi-Webster, C. M. (2018). Sentidos construídos sobre a internação em Comunidades Terapêuticas com pessoas em tratamento por uso de drogas. Psicologia em Estudo, 23.

Ministério da Saúde. (2003). A política do Ministério da Saúde para atenção integral a usuários de álcool e outras drogas.

Ministério da Saúde (2013). Recuperado de: http://www.ccs.saude.gov.br/saude_mental/pdf/sm_sus.pdf

Ministério da Saúde (2017). Portaria No 3.588. Recuperado de: http://bvsms.saude.gov.br/bvs/saudelegis/gm/2017/prt3588_22_12_2017.html

Ministério da Saúde (2019). Nota Técnica No 11/2019-CGMAD/DAPES/SAS/MS. Recuperado de: http://pbpd.org.br/wp-content/uploads/2019/02/0656ad6e.pdf 
Secretaria Geral da Presidência da República (2019). Decreto No 9.761. Recuperado de: http://www.planalto.gov.br/ccivil_03/_ato2019-2022/2019/decreto/D9761.htm

Siqueira, M. M., \& Silva, B. P. (2014). A Rede de Atenção aos Usuários de Álcool e outras Drogas. Centro Regional de Referência. Universidade Federal do Alagoas.

Merhy, E. E., \& Chakkour, M. (1997). Em busca de ferramentas analisadoras das tecnologias em saúde: a informação e o dia a dia de um serviço, interrogando e gerindo trabalho em saúde.

Monteiro, C.F.S., Fé, L. C. M., Moreira, M. A. C., Albuquerque, I. E. M., Silva, M. G., \& Passamani, M. C. (2001). Perfil sociodemográfico e adesão ao tratamento de dependentes de álcool em CAPSad do Piauí. Escola Anna Nery Revista de Enfermagem, 15(1):90-5.

Mororo, M. E. M. L., Colvero, L. D. A., \& Machado, A. L. (2011). Os desafios da integralidade em um Centro de Atenção Psicossocial e a produção de projetos terapêuticos. Revista da Escola de Enfermagem da USP, 45(5), 1171-1176.

Mota, D. C. B., \& Ronzani, T. M. (2013). Implementação de políticas públicas brasileiras para usuários de álcool e outras drogas. Ações Integradas sobre Drogas: prevenção, abordagens e políticas públicas. Juiz de Fora: Editora UFJF, P. 293-324.

Neves, C. A. B., \& Rollo, A. (2006). Acolhimento nas práticas de produção de saúde. Ministério da Saúde. Secretaria de Atenção à Saúde. Núcleo Técnico da Política Nacional de Humanização (Série B. Textos básicos em Saúde), 2.

Nicácio, F., \& de Sousa Campos, G. W. (2005). Instituições de" portas abertas": novas relações usuários-equipes-contextos na atenção em saúde mental de base comunitária/territorial. Revista de Terapia Ocupacional da Universidade de São Paulo, $16(1), 40-46$.

Nock, M. K., \& Ferriter, C. (2005). Parent management of attendance and adherence in child and adolescent therapy: A conceptual and empirical review. Clinical child and family psychology review, 8(2), 149-166.

Nunes, D. C. et al. Outras palavras sobre o cuidado de pessoas que usam drogas. Outras Palavras, p. 15, 2010. 
Nunes, M., Torrenté, M. D., Ottoni, V., Moraes Neto, V., \& Santana, M. (2008). A dinâmica do cuidado em saúde mental: signos, significados e práticas de profissionais em um Centro de Assistência Psicossocial em Salvador, Bahia, Brasil. Cadernos de Saúde Pública, 24, 188-196.

Oliveira, E. N. et al. (2013). Caracterização da clientela atendida em centro de atenção psicossocial: álcool e drogas.

Pitta, A. M. F., Silva Filho, J. F. D., Souza, G. W. D., Lancman, S., Kinoshita, R. T., Cavalcante, M. T., \& Valentini, W. H. (1995). Determinantes da qualidade de serviços de saúde mental em municípios brasileiros: estudo da satisfação com os resultados das atividades desenvolvidas por pacientes, familiares e trabalhadores dos serviços. Jornal Brasileiro de Psiquiatria, 44(9), 441-52.

Pereira, M. O., Amorim, A., Vidal, V., Falavigna, M. F., \& Oliveira, M. A. F. de. (2013). Busca ativa para conhecer o motivo da evasão de usuários em serviço de saúde mental. Acta Paulista de Enfermagem, 26(5), 409-412. https://dx.doi.org/10.1590/S010321002013000500002

Pichon-Rivière E. Teoria do Vínculo. 5.ed. São Paulo (SP): Martins Fontes, 1995.

Portaria $\mathrm{n}^{\mathrm{o}} 336$ (2002, 19 de fevereiro). Recuperado de: http://bvsms.saude.gov.br/bvs/saudelegis/gm/2002/prt0336_19_02_2002.html.

Portaria N $\mathrm{N}^{\mathrm{o}}$ 3.588, (2017, 21 de dezembro) - Recuperado de: http://138.68.60.75/images/portarias/dezembro2017/dia22/portaria3588.pdf

Recovery Library (2020, 20 de Fevereiro). Retrieved from https://recoverylibrary.unimelb.edu.au/domains/citizenship

Reis, L. F. (2016). Adesão dos dependentes de drogas psicoativas ao tratamento em CAPs AD.

Ribeiro, D. D. R., \& Carvalho, D. S. D. (2015). O padrão de uso de drogas por grupos em diferentes fases de tratamento nos Centros de Atenção Psicossocial Álcool e Drogas (CAPS-AD). Jornal Brasileiro de Psiquiatria, 64(3), 221-229. 
Ribeiro, J. M., Moreira, M. R., Bastos, F. I., Inglez-Dias, A., \& Fernandes, F. M. B. (2016). Acesso aos serviços de atenção em álcool, crack e outras drogas-o caso do município do Rio de Janeiro, Brasil. Ciência \& Saúde Coletiva, 21, 71-81.

Romanini, M., \& Fernandes, V. M. (2018). Os Processos de Autonomia no Cotidiano de um Caps Ad III:(Re) Pensando Práticas,(Re) Construindo Caminhos. Diálogo, (39), 09-23.

Salles, D. B., \& da Silva, M. L. (2017). Percepção de profissionais da área de saúde mental sobre o acolhimento ao usuário de substância psicoativa em CAPSad/Mental health professional perception of the embracement towards psychoactive substance user in CAPSad. Cadernos Brasileiros de Terapia Ocupacional, 25(2).

Silva, A. M. D. (2009). Tratamento do Centro de Atenção Psicossocial para usuários de álcool e outras drogas CAPSad II Leste Natal/RN: uma avaliação da efetividade (Master's thesis, Universidade Federal do Rio Grande do Norte).

Silva, A. B. D. (2018). Narrativas de cuidado de "usuários de drogas": um estudo etnográfico na rua e suas territorialidades.

Scheibel, A., \& Hecker Ferreira, L. (2012). Acolhimento no CAPS: reflexões acerca da assistência em saúde mental. Revista Baiana de Saúde Pública, 35(4), 966

Schneider, C. (2015). Consumo de drogas e internação compulsória: construção de um perfil sociodemográfico de usuários de um CAPS AD III.

Sequeira, C. (2014). Comunicação terapêutica em saúde mental. Revista Portuguesa de Enfermagem de Saúde Mental, (12), 6-8.

Shiokawa, E. (2010). Avaliação da eficiência da rede de atenção à saúde mental e da resolutividade do Centro de Atenção Psicossocial Álcool e Drogas - CAPS AD. (Tese de mestrado). Universidade Federal do Paraná, Brasil.

Silva, C. C., Costa, M. C. O., Carvalho, R. C. D., Amaral, M. T. R., Cruz, N. L. D. A., \& Silva, M. R. D. (2014). Iniciação e consumo de substâncias psicoativas entre adolescentes e adultos jovens de Centro de Atenção Psicossocial Antidrogas/CAPS-AD. Ciência \& Saúde Coletiva, 19, 737-745. 
Silva, N. D. S., Camargo, N. C. S., \& Bezerra, A. L. Q. (2018). Avaliação dos registros de procedimentos por profissionais de Centros de Atenção Psicossocial. Revista Brasileira de Enfermagem, 71, 2191-2198.

Silva, P. L. B., \& de Melo, M. A. B. (2000). O processo de implementação de políticas públicas no Brasil: características e determinantes da avaliação de programas e projetos. Unicamp.

Silva, D. L. S., \& Knobloch, F. (2016). A equipe enquanto lugar de formação: a educação permanente em um Centro de Atenção Psicossocial Álcool e outras drogas. InterfaceComunicação, Saúde, Educação, 20, 325-335.

Sobrosa, G. M. R., Zappe, J. G., Patias, N. D., Fiorin, P. C., \& Dias, A. C. G. (2014). O Desenvolvimento da Psicologia da Saúde a partir da construção da Saúde Pública no Brasil. Revista de Psicologia da IMED, 6(1), 4-9.

Souza, J. (2016). Crack e exclusão social

Souza, J. et al. A ralé brasileira: quem é e como vive. Belo Horizonte: editora UFMG, 2009.

Souza, L. K. D. (2019). Pesquisa com análise qualitativa de dados: conhecendo a Análise Temática. Arquivos Brasileiros de Psicologia, 71(2), 51-67.

Tammi T., \& Hurme T. (2007). How the harm reduction movement contrasts itself against punitive prohibition. Int J Drug Policy, 18:84-7.

Teesson, M., Baillie, A., Lynskey, M., Manor, B., \& Degenhardt, L. (2006). Substance use, dependence and treatment seeking in the United States and Australia: A cross-national comparison. Drug and Alcohol Dependence, 81(2), 149-155. doi: https://10.1016/j.drugalcdep.2005.06.007

Thorne, S. (2020). Beyond theming: Making qualitative studies matter. Nursing Inquiry, 27(1), e12343.

Tong, A., Sainsbury, P., \& Craig, J. (2007). Consolidated criteria for reporting qualitative research (COREQ): a 32-item checklist for interviews and focus groups. International journal for quality in health care, 19(6), 349-357. 
Tucker, j. A. (2001). Resolving problems associated with alcohol and drug misuse: understanding relations between addictive behavior change and the use of services. Substance use \& misuse, 36(11), 1501-1518. Recuperado de:https://doi.org/10.1081/JA100106961

Turato, E. (2005). Métodos quantitativos e qualitativos na área da saúde: definições, diferenças e seus objetos de pesquisa. Rev Saúde Pública, 39(3).

Vaissman, M., Ramôa, M., \& Serra, A. S. V. (2008). Panorama do tratamento dos usuários de drogas no Rio de Janeiro. Saúde em Debate, v. 32, ns. 78/80, p. 121-132, 2008.

Vasters, G. P., \& Pillon, S. C. (2011). Drugs use by adolescents and their perceptions about specialized treatment adherence and dropout. Revista latino-americana de enfermagem, 19(2), 317-324.

Xavier, R. T., \& Monteiro, J. K. (2013). Tratamento de Pacientes Usuários de crack e outras drogas nos CAPS AD. Psicologia Revista, 22(1), 61-82.

Wandekoken, K. D., \& Siqueira, M. M. (2011). Discursos políticos e a rede de atenção aos usuários de substâncias psicoativas. Saúde e Debate, v. 35, n. 88, p. 105-112.

Wetzel, C., \& Kantorski, L. P. (2004). Avaliação de serviços em saúde mental no contexto da reforma psiquiátrica. Texto \& Contexto-Enfermagem, 13(4), 543-548.

Willig, C. (2001). Introducing qualitative research in psychology: adventures in theory and method. New York - USA: Open University Press.

Wodak A. (2009). Harm reduction is now the mainstream global drug policy. Addiction, 104:343-5.

World Health Organization (WHO) (2003) Adherence to long-term therapies Project: Evidence for action. Geneva: WHO Press, 2003: 194.

World Health Organization (WHO) (2019) Using qualitative research to strengthen guideline development. Recuperado em: https://www.who.int/reproductivehealth/QES-forguidelines/en/ 
Wu, P., Hoven, C. W., Tiet, Q., Kovalenko, P., \& Wicks, J. (2002). Factors associated with adolescent utilization of alcohol treatment services. The American Journal of Drug and Alcohol Abuse, 28(2), 353-369. doi:10.1081/ada-120002978 
Apêndices 



\section{APÊNDICE A}

\section{FICHA DE DADOS SÓCIODEMOGRÁFICOS}

Data de Preenchimento:

AS PRÓXIMAS PERGUNTAS REFEREM-SE A INFORMAÇÕES SOBRE VOCÊ, SUA FAMÍLIA E O LOCAL ONDE MORA.

Nome:

Nome social:

Data de Nascimento:

Idade:

Estado civil: ( ) Solteiro ( ) Casado/Amasiado ( ) Divorciado ( ) Viúvo ( ) Separado

Raça/Cor: ( ) Branca ( ) Preta ( ) Parda ( ) Amarela ( ) Indígena ( ) Não declarado

Identidade de gênero: ( ) Homem ( ) Mulher ( ) Homem Trans ( ) Mulher Trans ( )Travesti

Religião: ( ) Católico ( ) Evangélico ( ) Espírita ( ) Ateu ( ) Outras

Praticante: ( ) Não ( ) Sim

Escolaridade:

( ) Nunca estudou

( ) Fundamental incompleto

( ) Fundamental completo

( ) Médio incompleto

( ) Médio completo

Situação ocupacional atual:

( ) Estudante

( ) Trabalha registrado

( ) Trabalha e não é registrado

( ) Autônomo

( ) Desempregado

( ) Aposentado

( ) Do lar
( ) Superior incompleto

( ) Superior completo

( ) Curso técnico incompleto

( ) Curso técnico completo

( ) Pós-Graduação

( ) Nunca trabalhou 
Qual a profissão?

Em relação a seu emprego, você:

( ) Sente-se satisfeito

( ) Gostaria de mudar. Por quê?

Se desempregado, quanto tempo?

Recebe benefícios sociais? ( ) não ( ) sim. Qual

Você tem renda própria? ( ) não ( ) sim

Renda mensal familiar: reais

Maior responsável pelo sustento da família:

Quantas pessoas (adultos e crianças), incluindo você, dependem desta renda para sobreviver?

Número de filhos:

Moram com você? ( ) não ( ) sim

Com quem você mora:

Em relação ao local onde mora, você considera-se:

( ) Satisfeito

( ) Não satisfeito. Por quê?

Informações sobre a residência e entorno

\begin{tabular}{|l|l|l|l|l|l|}
\hline Área de Serviço & & Televisão & Pavimentação & \\
\hline Banheiro & & Geladeira & & Rede de esgoto & \\
\hline Cozinha & & Máquina de roupas/Tanquinho & & Abastecimento de água & \\
\hline Garagem & & Fogão & & Coleta de lixo & \\
\hline Quarto & & Automóvel & Energia elétrica & \\
\hline Sala & & Moto & Iluminação pública & \\
\hline Áreas Abandonadas & & & &
\end{tabular}




\section{APÊNDICE B}

\section{ROTEIRO DE ENTREVISTA SEMIESTRUTURADA}

\section{Início e padrão de consumo de substância(s):}

- Quando iniciou o consumo de substância? Qual substância?

- Quais motivos levaram ao uso?

-Faz uso regular dessa(s) substância(s)?

-Como é o padrão de consumo dessa(s) substância (s)?

-Considera um problema o uso dessa(s) substância(s)?

-Se sim, por quê?

-Se não, por quê?

- Convive com alguma pessoa que faz uso de alguma substância?

- Quem?

- Qual/quais substância(s)?

- Compartilham o uso?

\section{O percurso pela Rede AD}

- O que você procurou para te ajudar?

- Permaneceu em algum? Se sim, por quanto tempo?

- Quais atividades frequentou/frequenta?

- Neste percurso, alguém indicou o CAPS ad? Como foi? Teve dificuldade ao acesso?

\section{A busca pelo CAPS ad e sua vivência}

- Já conhecia o CAPS ad antes da procura pelo serviço?

-Como chegou até o CAPS ad? 
-Como foi recebido?

- Quando esteve no CAPS quanto tempo permaneceu?

-Quais atividades participou no CAPS ad?

-Conte-me um pouco sobre elas.

\section{Características das relações com a equipe e com usuários do equipamento que} dificultaram na adesão do indivíduo à proposta terapêutica

- Como era a relação com os profissionais do serviço?

- Como era a relação com os demais usuários do serviço?

- O que você esperava do CAPS?

- O que você não encontrou? E o que você encontrou e que esperava?

- Teve algo que te surpreendeu positivamente?

- Teve algo que você acha que o CAPS ajudou?

- O que você acha que o CAPS poderia fazer para te ajudar?

- Por que você interrompeu o tratamento?

\section{Pós CAPS ad}

- Após optar em não ficar em tratamento no CAPS ad, procurou outra forma de ajuda para lidar com o uso de drogas?

-Qual? Conte-me um pouco sobre ela(s).

- Por quanto tempo permaneceu?

- O que essa atividade ofereceu que você não encontrou no CAPS ad? 


\section{APÊNDICE C}

\section{TERMO DE CONSENTIMENTO LIVRE E ESCLARECIDO}

Sabemos que o tratamento devido ao uso de drogas é um percurso difícil e ainda pode ocorrer junto com outras questões de saúde. Uma das modalidades terapêuticas de tratamento preconizado pela Reforma Psiquiátrica e referido como serviço de referência na rede de atenção aos usuários de drogas é o Centro de Atenção Psicossocial para Álcool e Drogas (CAPS AD). Neste projeto temos como objetivo compreender, sob a perspectiva do usuário, dificuldades para iniciar e dar continuidade ao tratamento em um Centro de Atenção Psicossocial Álcool e outras Drogas (CAPS AD). Você está sendo convidado a participar do estudo "A adesão ao tratamento nos Centros de Atenção Psicossocial Álcool e outras Drogas sob a perspectiva do usuário”. Iremos fazer algumas perguntas sobre estes temas e pedimos sua autorização para gravarmos esta conversa, para garantir que as informações tenham melhor qualidade e fidedignidade. Gostaríamos de esclarecer que: seu nome será mantido em sigilo; as informações que você nos der serão confidenciais e serão usadas apenas para este estudo; estas informações poderão ser publicadas e/ou apresentadas com objetivo científico, entretanto, não será possível identificar as pessoas envolvidas. Sua participação é voluntária, sem nenhum tipo de pressão, isto é, você não é obrigado a participar deste estudo e se desejar a qualquer momento não participar mais, sua decisão será respeitada. Caso a entrevista provoque algum desconforto você poderá interrompê-la a qualquer momento, no qual poderemos conversar sobre o desconforto, caso essa seja a sua vontade. A única coisa que lhe pedimos é o tempo para responder a entrevista, sendo que esse não atrapalhará nenhuma atividade. Prevemos que o tempo de duração da entrevista seja entre 40 minutos à uma hora. Caso alguma dúvida ou mal-estar apareça estaremos disponíveis para ajudar. As informações prestadas por você serão muito úteis para compreendermos melhor como é o processo de procura pelo CAPS AD por aqueles que consomem drogas/bebidas alcoólicas e, com isto, melhor compreender os serviços que oferecemos.

Se você concordar em participar da pesquisa, queremos esclarecer que:

a) você é livre para, a qualquer momento, recusar-se a responder às perguntas que lhe ocasionem constrangimento de qualquer natureza;

b) você pode deixar de participar da pesquisa a qualquer momento e não precisa apresentar justificativas para isso.

c) não haverá nenhuma forma de reembolso de dinheiro para esta participação, já que você não terá nenhum gasto.

Agradecemos sua colaboração e colocamo-nos à disposição para esclarecimentos que se fizerem necessários. Este termo está em duas vias, uma ficará com você e outra com o pesquisador.

Estando de acordo:

Nome do participante

Assinatura do participante
Nome da entrevistadora

Assinatura da entrevistadora

Se precisar de algum outro tipo de esclarecimento sobre o estudo, você pode entrar em contato com as pesquisadoras responsáveis:

Prof. ${ }^{\text {a }}$ Dr. ${ }^{\text {a }}$ Clarissa Mendonça Corradi-Webster

Departamento de Psicologia

Faculdade de Filosofia, Ciências e Letras de Ribeirão Preto - USP

(16) 3315.0196

clarissac@usp.br
Larissa Soares de Melo

Mestranda do Departamento de Psicologia

Faculdade Filosofia, Ciências e Letras de Ribeirão Preto USP

(16) 99646-4646

larissamelo@usp.com

Assinatura da pesquisadora responsável:

Se precisar de algum outro tipo de esclarecimento referente aos aspectos éticos da pesquisa, entre em contato: Comitê de Ética em Pesquisa da Faculdade de Filosofia, Ciências e Letras de Ribeirão Preto - USP, Avenida Bandeirantes, 3900 - bloco 01 - Prédio da Administração - sala 07 - CEP 14040-901 - Ribeirão Preto - SP - Brasil

Fone: (16) 3315-4811 / Fax: (16) 3633-2660 E-mail: coetp@ffclrp.usp.br / homepage: http://www.ffclrp.usp.br 


\section{APÊNDICE D}

\section{TERMO DE CONSENTIMENTO PARA A FORMAÇÃO DE BANCO DE DADOS}

Prezado (a) participante você foi convidado (a) a participar do projeto de pesquisa "Dificuldades para adesão ao tratamento em Centro de Atenção Psicossocial Álcool e outras Drogas: perspectiva do usuário" conduzida pela mestranda Larissa Soares de Melo com a orientação da Prof $^{a}{ }^{\text {Dra }}{ }^{a}$. Clarissa Mendonça Corradi-Webster, docente da Faculdade de Filosofia, Ciências e Letras de Ribeirão Preto da universidade de São Paulo (FFCLRP-USP). A partir do seu consentimento, gostaríamos de consultá-lo sobre a possibilidade do armazenamento de todas as informações coletadas, obtidos através da sua participação. Caso você autorize, as informações coletadas por meio de gravações e transcrições serão armazenadas por tempo indeterminado em um banco de dados digital. Isto permite que os dados sejam analisados mais facilmente pelos pesquisadores, podendo inclusive contribuir para que novas pesquisas sejam realizadas a partir dos dados que já estão armazenados, ajudando a gerar novos conhecimentos sobre o cuidado dos usuários de drogas. Asseguramos que todas as informações prestadas e armazenadas são estritamente confidenciais, e qualquer pesquisa e publicação envolvendo estes dados não incluirão nomes ou informações que possam identificá-lo, garantindo seu anonimato em todo o processo.

Caso deseje autorizar este processo, basta assinar este termo, e mesmo que não queira autorizar o armazenamento dos dados neste banco digital, ainda é possível participar da pesquisa desde que seja assinado o TCLE. Além disso, seu consentimento pode ser retirado a qualquer momento, não havendo nenhum prejuízo ou dano para você. Fica também ao seu critério de escolha se gostaria de ser avisado, ou não, a cada nova pesquisa utilizando os dados coletados e armazenados, que para seu conhecimento passará novamente pelo Comitê de Ética em Pesquisa da Faculdade de Filosofia Ciências e Letras de Ribeirão Preto - USP que pode ser contatado a qualquer momento para esclarecimentos referentes aos aspectos éticos, através do endereço: Avenida Bandeirante, 3900 - bloco 01 - Prédio da Administração sala 07 - 14040-901. Bairro Monte Alegre. Ribeirão Preto - SP - Brasil/ telefone: (16) 3315-4811. E-mail: coetp@listas.ffclrp.usp.br. Se precisar de algum outro tipo de esclarecimento sobre o estudo, você poderá entrar em contato com as pesquisadoras responsáveis pela pesquisa do Departamento de Psicologia da FFCLRP - USP: Prof ${ }^{a}$ Dr $^{a}$ Clarissa Mendonça Corradi-Webster (clarissac@usp.br/(16) 3315-0196), Mestranda Larissa Soares de Melo (larissamelo@usp.br/(16)99646-4646)

Atenciosamente,

Prof $^{\mathrm{a}}$ Dr $^{\mathrm{a}}$ Clarissa Mendonça Corradi-Webster

Mestranda Larissa Soares de Melo

Autorização par formação de banco de dados da pesquisa "Dificuldades para adesão ao tratamento em Centro de Atenção Psicossocial Álcool e outras Drogas: perspectiva do usuário"

Ribeirão Preto, de de 201

Eu,

declaro que fui informado(a) dos objetivos e procedimentos do trabalho e autorizo o armazenamento dos dados no banco de dados digital. Autorizo também a utilização de todos os dados coletados em futuras pesquisas, desde que garantido meu sigilo. Declaro que possuo uma via deste Termo que ora aceito. Sei que a qualquer momento posso revogar este aceite, sem a necessidade de prestar qualquer informação adicional.

( ) Quero ser avisado todas as vezes que meus dados forem utilizados em futuras pesquisas.

( ) Não quero ser avisado quando meus dados forem utilizados em futuras pesquisas.

Assinatura do participante: 
Anexos 



\section{ANEXO A - APROVAÇÃO COMITÊ DE ÉTICA}

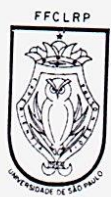

Universidade de São Paulo

Faculdade de Filosofia, Ciências e Letras de Ribeirão Preto Comitê de Ética em Pesquisa

Of.CEtP/FFCLRP-USP/021-dgfs.

Campus de Ribeirão Preto

Ribeirão Preto, 27 de março de 2018.

Prezado(a) Pesquisador(a),

Comunicamos a V. Sa. que o projeto de pesquisa intitulado "Dificuldades para adesão ao tratamento em Centro de Atenção Psicossocial Álcool e outras Drogas: perspectiva do usuário." foi analisado pelo Comitê de Ética em Pesquisa da FFCLRP-USP, em sua 176a Reunião Ordinária, realizada em 22.03.2018, e enquadrado na categoria: APROVADO (CAAE n 82490517.0.0000.5407).

Solicitamos que eventuais modificações ou emendas ao projeto de pesquisa sejam apresentadas ao CEP, de forma sucinta, identificando a parte do projeto a ser modificada e suas justificativas. De acordo com a Resolução n466 de 12/12/2012, devem ser entregues relatórios semestrais e, ao término do estudo, um relatório final sempre via Plataforma Brasil.

Atenciosamente,

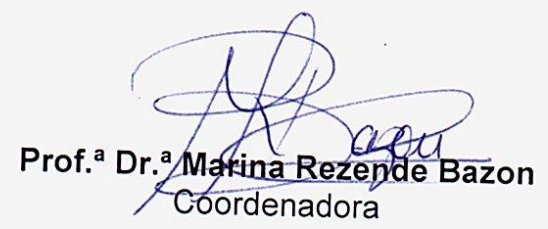

Ao(À) Senhor(a)

Larissa Soares De Melo

Programa de Pós-graduação em Psicologia da FFCLRP-USP

CEP - Comitê de Ética em Pesquisa da FFCLRP USP

14040-901 - Ribeirão Preto - SP - Brasil

Hom-901 - Ribeira Preto - SP - Brasil

Homepage: http://www.ffclrp.usp.br - e-mail: coetp@ffclrp.usp.br 


\section{ANEXO B - COMPROVANTE SUBMISSÃO}

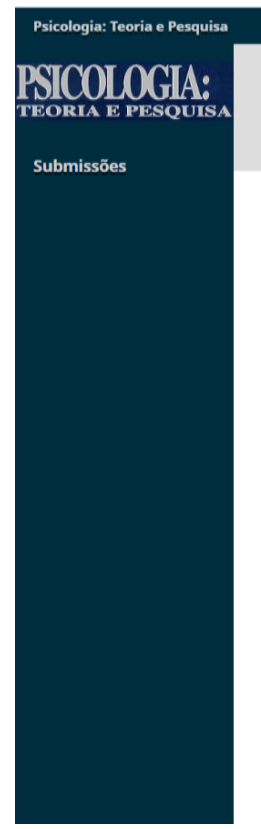

\section{Tarefas 0}

Submeter um artigo

$\begin{array}{llll}\text { 1. Início } & \text { 2. Transferência do manuscrito } & \text { 3. Dados da Submissão } & \text { 4. Confirmaçăo }\end{array}$

5. Próximos Passos

\section{Submissão completa}

Obrigado pelo seu interesse em publicar com Psicologia: Teoria e Pesquisa.

\section{o que acontece a seguir?}

O periódico foi notificado de sua submissão e um e-mail de confirmação foi enviado para seu registro. Assim que um dos editores revisar sua submissão entrará em contato.

Por enquanto, você pode:

- Avaliar esta submissã̃o

- Criar uma nova submissão

- voltar para seu painel

Agradecemos a submissão do trabalho "Relações interpessoais no tratamento do usuário de drogas como dificultador à adesão: Relaç̃os e adesão no tratamento ao uso de drogas" para a revista Psicologia: Teoria e Pesquisa.

Acompanhe o progresso da sua submissão por meio da interface de administração do sistema, disponivel em:

URL da submissão: https://periodicos. unb.br/index php/revistaptplauthorDashboard/submission/29937 Login: larissa_melo11

Em caso de dúvidas, entre em contato via e-mail.

Agradecemos mais uma vez considerar nossa revista como meio de compartilhar seu trabalho

Elaine Rabelo Neiva

PSICOLOGIA: TEORIAE PESQUISA

Instituto de Psicologia da Universidade de Brasilia

http./l/periodicos. unb. br/index.php/revistaptp | +55 $613107-6826$ 


\section{ANEXO C - COMPROVANTE SUBMISSÃO}

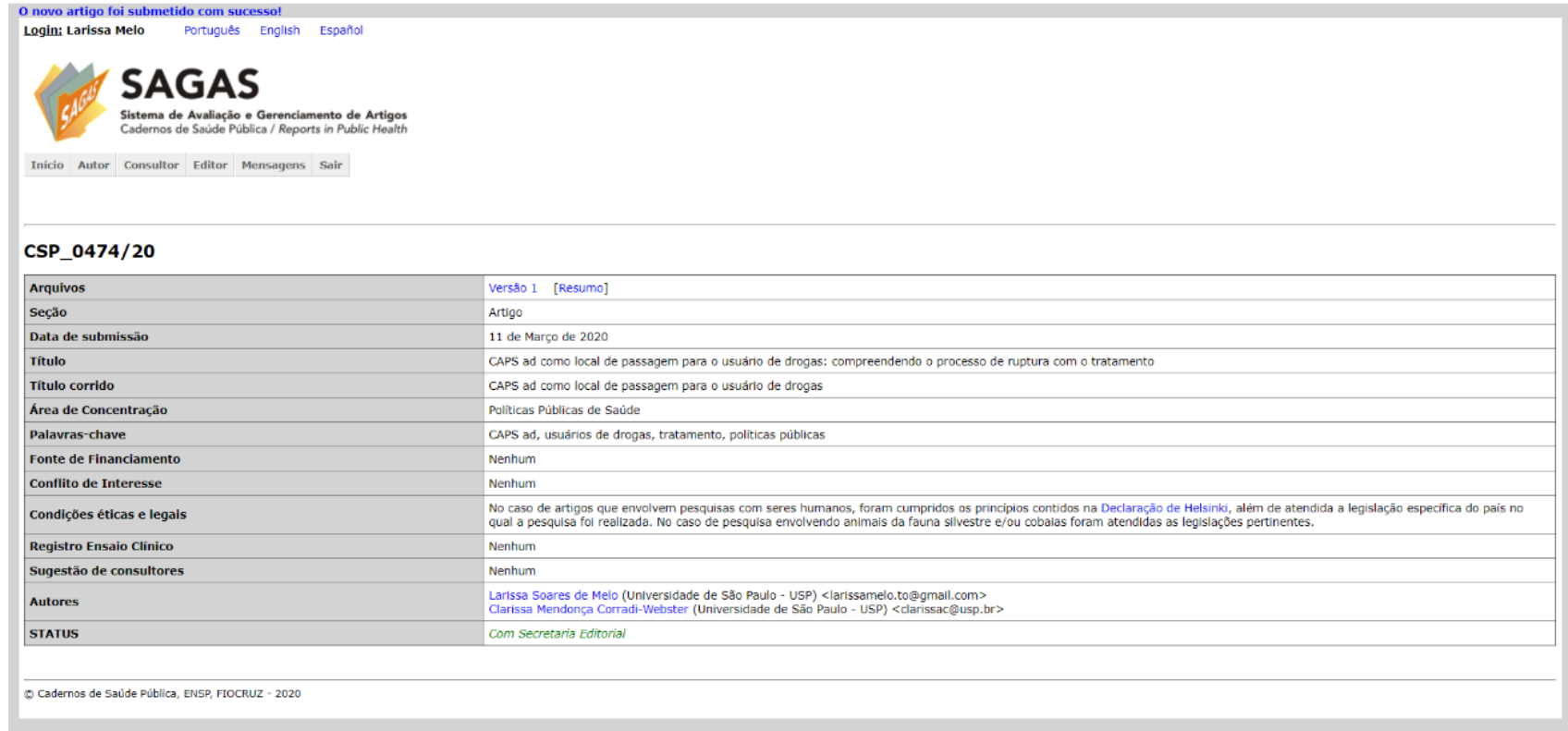

Prezado(a) Dr(a). Larissa Soares de Melo:

Confirmamos a submissão do seu artigo "CAPS ad como local de passagem para o usuário de drogas: compreendendo o processo de ruptura com o tratamento" (CSP_0474/20) para Cadernos de Saúde Pública. Agora será possível acompanhar o progresso de seu manuscrito dentro do processo editorial, bastando clicar no link "Sistema de Avaliação e Gerenciamento de Artigos", localizado em nossa página http://www.ensp.fiocruz.br/csp.

Em caso de dúvidas, envie suas questões através do nosso sistema, utilizando sempre o ID do manuscrito informado acima. Agradecemos por considerar nossa revista para a submissão de seu trabalho.

Atenciosamente,

Profa. Marilia Sá Carvalho

Profa. Claudia Medina Coeli

Profa. Luciana Dias de Lima

Editoras

Cadernos de Saúde Pública / Reports in Public Health

Escola Nacional de Saúde Pública Sergio Arouca

Fundaçăo Oswaldo Cruz

Rio de Janeiro, RJ 21041-210, Brasil

Tel.: +55 (21) 2598-2511, 2508 / Fax: + 55 (21) 2598-2737

cadernos@ensp.fiocruz.br

http://www.ensp. fiocruz.br/csp 
